\title{
Two Unusual Epicatechin and Epiafzelechin Derivatives from Mascagnia pubiflora, a Plant Toxic to Cattle
}

\author{
Walmir S. Garcez, ${ }^{*, a}$ Fernanda R. Garcez, ${ }^{a}$ Deizeluci de F. P. Zanella, ${ }^{a, b}$ Lidilhone Hamerski, ${ }^{a}$ \\ Antonio G. Ferreira, ${ }^{c}$ Andersson Barison ${ }^{c}$ and Alfredo R. Abot ${ }^{b}$
}

\author{
${ }^{a}$ Departamento de Química Universidade Federal de Mato Grosso do Sul, 79070-900 Campo Grande-MS, Brazil \\ ${ }^{b}$ Universidade Estadual de Mato Grosso do Sul, Unidade Universitária de Aquidauana, \\ 79200-000 Aquidauana-MS, Brazil
}

${ }^{c}$ Departamento de Química, Universidade Federal de São Carlos, 13560-970 São Carlos-SP, Brazil

\begin{abstract}
Dois novos e incomuns derivados de epicatequina e epiafzelequina contendo unidades feniloctanóides glicosiladas e denominados mascagninas A e B foram isolados, juntamente com quercetina-3-O- $\alpha$-L-ramnopiranosil-(1 $\rightarrow 6$ )- $\beta$-D-glucopiranosídeo, das partes aéreas de Mascagnia pubiflora (Malpighiaceae), uma planta tóxica para o gado. Suas estruturas foram determinadas pela combinação de espectroscopia de ressonância magnética nuclear (RMN) uni e bidimensionais e dados de espectroscopia de massas (MS).
\end{abstract}

\begin{abstract}
Mascagnins A and B, two novel and unusual epicatechin and epiafzelechin derivatives bearing glucosylated phenyloctanoid units, along with quercetin-3- $O-\alpha$-L-rhamnopyranosyl- $(1 \rightarrow 6)-\beta-\mathrm{D}-$ glucopyranoside were isolated from the aerial parts of Mascagnia pubiflora (Malpighiaceae), a plant toxic to cattle. Their structures were established by a combination of 1D- and 2D-nuclear magnetic resonance spectroscopic techniques and mass spectrometry data.
\end{abstract}

Keywords: Mascagnia pubiflora, Malpighiaceae, poisonous plant, phenyloctanoid catechins

\section{Introduction}

In Brazil, poisoning by plants is one of the main causes of death to adult cattle and the number of plants which are considered to be toxic to ruminants is constantly increasing. ${ }^{1,2}$ Therefore, considerable losses due to cattle intoxication by ingestion of seeds, leaves or roots of toxic plants have become a significant problem in cattle producing areas. In the state of Mato Grosso do Sul, Brazil's greatest producer of pasture-herd cattle, $M$. pubiflora (Mascagnia pubiflora) (A. Juss.) Griseb., a liana popularly known as "cipó prata" and "corona" that belongs to the Malpighiaceae family, is the main causative agent of sudden bovine death as a consequence of heart attack, due to a peracute poisoning. ${ }^{2,3}$ The cardiotoxic activity of M. pubiflora was studied by Saad et al. ${ }^{4}$ in 1970, and attempts to isolate and characterize the active principles pointed to the possibility of the presence

*e-mail: wgarcez@nin.ufms.br of a biologically active glycoside. ${ }^{4}$ Considering the economic losses due to the toxic activity of M. pubiflora on grazing animals and the absence of a more detailed phytochemical study, we decided to investigate the chemical composition of the aerial parts of a specimen of M. pubiflora growing in the "Pantanal" border of Mato Grosso do Sul. Herein, we report on the isolation of two novel and unusual epicatechin and epiafzelechin derivatives bearing glucosylated phenyloctanoid units, named mascagnins $\mathrm{A}$ and $\mathrm{B}$, together with quercetin-3-O$\alpha$-L-rhamnopyranosyl-( $1 \rightarrow 6)-\beta$-D-glucopyranoside.

\section{Results and Discussion}

Dried and ground aerial parts of M. pubiflora were extracted with EtOH. After removal of the solvent, the residue was subsequently partitioned between $1: 1 \mathrm{MeOH}-$ $\mathrm{H}_{2} \mathrm{O}$ and $\mathrm{CHCl}_{3}$ and 1:1 MeOH-H $\mathrm{H}_{2} \mathrm{O}$ and EtOAc. After a combination of column chromatography on reversed phase silica gel, gel filtration and reversed phase high performance 
liquid chromatography (HPLC) separations of the EtOAc phase, compounds 1 (mascagnin A), 2 (mascagnin B) and a known flavonoid diglycoside, quercetin-3-O- $\alpha-\mathrm{L}-$ rhamnopyranosyl- $(1 \rightarrow 6)-\beta$-D-glucopyranoside $(3)$ were isolated.

Compound 1 was obtained as an amorphous powder and its molecular formula was suggested to be $\mathrm{C}_{55} \mathrm{H}_{70} \mathrm{O}_{24}$ on the basis of the quasi-molecular ion peak at $m / z 1113.3706$ $[\mathrm{M}-\mathrm{H}]^{-}$in the high resolution electron spray ionization mass spectrum (HRESIMS) and on NMR data. The molecular formula pointed to twenty-one degrees of unsaturation for the compound. Its IR spectrum showed absorption bands for hydroxyl $\left(3410 \mathrm{~cm}^{-1}\right)$ and aromatic $\left(1617,1510 \mathrm{~cm}^{-1}\right)$ functionalities. The ${ }^{1} \mathrm{H}$ and ${ }^{13} \mathrm{C}$ NMR spectra of $\mathbf{1}$ (Table 1) exhibited signals for fifteen aromatic quaternary carbons (nine oxygenated) and nine aromatic methine carbons, thus indicating the presence of four aromatic rings in its structure. In addition, signals attributable to carbons of aliphatic moieties were assigned to two methyls, nine methylenes, six methines (four oxymethines), and two oxygenated quaternary carbons. Additionally, twelve carbon signals corresponding to two sugar residues were also observed and were assigned to two D-glucopyranosyl units. ${ }^{5,6}$ The anomeric centers were each determined to have a $\beta$-configuration based on the coupling constant values of the $\alpha$-oriented anomeric proton signals, which were observed as a two-proton doublet at $\delta_{\mathrm{H}} 4.64(\mathrm{~J} 7.3 \mathrm{~Hz})^{5,6}$ This, in turn, showed cross-peak correlations in the heteronuclear single quantum coherence (HSQC) spectrum with the signals at $\delta 104.5$ and 104.8 , accounting for the two anomeric carbons, whose chemical shifts around 100 ppm indicated the $O$-glucosidic nature of $\mathbf{1} .^{5,6}$

Three of the four aromatic rings were found to be 1,2,4-trisubstituted, as ascertained by the connectivities

Table 1. ${ }^{1} \mathrm{H}(400 \mathrm{MHz})$ and ${ }^{13} \mathrm{C}(100 \mathrm{MHz})$ spectral data of $\mathbf{1}$

\begin{tabular}{|c|c|c|c|c|c|c|c|}
\hline No & $\delta_{\mathrm{C}}^{\mathrm{a}}$ & $\delta_{\mathrm{H}}(\mathrm{J} \text { in } \mathrm{Hz})^{\mathrm{a}}$ & $\mathrm{HMBC}(\mathrm{H} \rightarrow \mathrm{C})$ & No & $\delta_{\mathrm{C}}^{\mathrm{a}}$ & $\delta_{\mathrm{H}}{ }^{\mathrm{a}}$ & $\mathrm{HMBC}(\mathrm{H} \rightarrow \mathrm{C})$ \\
\hline 2 & 79.9 & $4.68 \mathrm{brs}$ & C-1', C-2', C-6', C-3, C-4 & $11 \mathrm{a}$ & 148.0 & - & \\
\hline 3 & 67.1 & $4.19 \mathrm{brs}$ & C-10 & $12 \mathrm{a}$ & 145.9 & - & \\
\hline 4 & 29.5 & $\begin{array}{c}2.82 \text { brd }(16.7) \\
2.95 \mathrm{dd}(16.7,4.0)\end{array}$ & $\begin{array}{c}\mathrm{C}-2, \mathrm{C}-3, \mathrm{C}-5, \mathrm{C}-9, \mathrm{C}-10 \\
\mathrm{C}-5, \mathrm{C}-9, \mathrm{C}-10\end{array}$ & $13 \mathrm{a}$ & 119.0 & $7.00 \mathrm{~d}(8.3)$ & C-9a, C-11a \\
\hline 5 & 151.7 & - & & $14 \mathrm{a}$ & 121.1 & $6.57 \mathrm{dd}(8.3,1.9)$ & C-8a, C-10a, C-12a \\
\hline 6 & 105.3 & - & & $1 b$ & 24.9 & $3.42 \mathrm{~m}$ & $\mathrm{C}-8, \mathrm{C}-2 \mathrm{~b}, \mathrm{C}-5 \mathrm{~b}$ \\
\hline 7 & 154.0 & - & & $2 b$ & 35.4 & $\begin{array}{c}1.69 \mathrm{~m} \\
1.97 \mathrm{dd}(12.4,2.8)\end{array}$ & $\mathrm{C}-3 \mathrm{~b}$ \\
\hline 8 & 105.6 & - & & $3 b$ & 98.8 & - & \\
\hline 9 & 150.9 & - & & $4 b$ & 28.5 & $1.52 \mathrm{~s}$ & $C-2 b, C-3 b$ \\
\hline 10 & 99.5 & - & & $5 b$ & 36.8 & $\begin{array}{l}1.53 \mathrm{~m} \\
1.64 \mathrm{~m}\end{array}$ & $C-1 b, C-2 b, C-9 b$ \\
\hline $1^{\prime}$ & 132.6 & - & & $6 b$ & 70.0 & $3.57 \mathrm{~m}$ & \\
\hline $2^{\prime}$ & 115.1 & $6.96 \mathrm{~d}(1.6)$ & C-2, C-4', C-6' & $7 b$ & 39.7 & $\begin{array}{c}1.47 \mathrm{~m} \\
1.66-1.71 \mathrm{~m}\end{array}$ & \\
\hline $3^{\prime}$ & 145.9 & - & & $8 \mathrm{~b}$ & 32.2 & $\begin{array}{l}2.30 \mathrm{~m} \\
2.57 \mathrm{~m}\end{array}$ & $C-7 b, C-9 b, C-10 b, C-14 b$ \\
\hline $4^{\prime}$ & 145.8 & - & & $9 b$ & 139.6 & - & \\
\hline $5^{\prime}$ & 116.4 & $6.78 \mathrm{~d}(8.2)$ & C-1', C-3' & $10 \mathrm{~b}$ & 117.1 & $6.60 \mathrm{~d}(1.9)$ & $C-8 b, C-12 b, C-14 b$ \\
\hline $6^{\prime}$ & 119.3 & $6.75 \mathrm{dd}(8.2,1.6)$ & C-2, C-2', C-4' & $11 b$ & 147.8 & - & \\
\hline $1 \mathrm{a}$ & 24.9 & $3.40 \mathrm{~m}$ & C-6, C-2a, C5a & $12 b$ & 144.7 & - & \\
\hline $2 \mathrm{a}$ & 35.6 & $\begin{array}{c}1.69 \mathrm{~m} \\
1.97 \mathrm{dd}(12.4,2.8)\end{array}$ & C-3a & $13 b$ & 118.9 & $6.99 \mathrm{~d}(8.3)$ & C-9b, C-11b \\
\hline $3 \mathrm{a}$ & 98.9 & - & & $14 b$ & 120.9 & $6.51 \mathrm{dd}(8.3,1.9)$ & $C-8 b, C-10 b, C-12 b$ \\
\hline $4 a$ & 28.5 & $1.47 \mathrm{~s}$ & $C-1 a, C-2 a, C-3 a$ & $1 "$ & $104.8 / 104.5$ & $4.64 / 4.64 \mathrm{~d}(7.3)$ & $C-12 a, C-12 b$ \\
\hline $5 \mathrm{a}$ & 36.8 & $\begin{array}{c}1.60 \mathrm{~m} \\
1.88 \text { brd (13.4) }\end{array}$ & C-1a, C-2a, C-9a & $2 "$ & $74.8 / 74.8$ & $3.43 \mathrm{~m}$ & \\
\hline $6 a$ & 70.8 & $3.53 \mathrm{~m}$ & & $3 "$ & $78.1 / 78.0$ & $3.33-3.39 \mathrm{~m}$ & \\
\hline $7 \mathrm{a}$ & 39.7 & $\begin{array}{c}1.47 \mathrm{~m} \\
1.66-1.71 \mathrm{~m}\end{array}$ & & $4 "$ & $71.3 / 71.2$ & $3.35-3.42 \mathrm{~m}$ & \\
\hline $8 \mathrm{a}$ & 31.6 & $2.46 \mathrm{~m}$ & C-7a , C-9a, C-10a, C-14a & $5 "$ & $77.5 / 77.4$ & $3.43 \mathrm{~m}$ & \\
\hline $9 \mathrm{a}$ & 139.4 & - & & $6 "$ & $62.5 / 62.3$ & $3.85-3.68 \mathrm{~m}$ & \\
\hline $10 \mathrm{a}$ & 117.4 & $6.62 \mathrm{~d}(1.9)$ & $\mathrm{C}-8 \mathrm{a}, \mathrm{C}-12 \mathrm{a}, \mathrm{C}-14 \mathrm{a}$ & & & & \\
\hline
\end{tabular}

${ }^{a}$ Assignments of H/C 1a-14a may be interchanged with those of H/C 1b-14b. 
observed in ${ }^{1} \mathrm{H}-{ }^{1} \mathrm{H}$ correlation spectroscopy (COSY) spectrum, in which three spin systems could be assigned by the signals at $\delta 6.57(\mathrm{dd}, J 8.3$ and $1.9 \mathrm{~Hz}), 7.00(\mathrm{~d}, J 8.3 \mathrm{~Hz})$ and $6.62(\mathrm{~d}, J 1.9 \mathrm{~Hz})[\mathrm{I}] ; \delta 6.51(\mathrm{dd}, J 8.3$ and $1.9 \mathrm{~Hz}), 6.99$ $(\mathrm{d}, J 8.3 \mathrm{~Hz})$ and $6.60(\mathrm{~d}, J 1.9 \mathrm{~Hz})[\mathrm{II}]$ and $\delta 6.75(\mathrm{dd}, J 8.2$ and $1.6 \mathrm{~Hz}), 6.78(\mathrm{~d}, J 8.2 \mathrm{~Hz})$ and $6.96(\mathrm{~d}, J 1.6 \mathrm{~Hz})[\mathrm{III}]$. In addition, the respective $\mathrm{HSQC}$ and heteronuclear multiple bond correlations (HMBC) along with the corresponding aromatic carbon resonances indicated the presence of one alkyl and two ortho-oxygenated substituents in each of the aromatic rings. The absence of other proton resonances in the aromatic region of the ${ }^{1} \mathrm{H}$ NMR spectrum as well as the presence of six quaternary carbon signals ascribable to aromatic carbons in the ${ }^{13} \mathrm{C}$ NMR spectrum defined the fourth aromatic ring in the structure of $\mathbf{1}$ as a hexasubstituted one. The chemical shifts assigned to the carbons of this ring at $\delta 99.5,105.3,105.6,150.9,151.7$ and 154.0 matched to an 1,3,5-trioxygenated aromatic ring bearing alkyl residues at the 2,4 and 6 positions.

Another spin system detected in the ${ }^{1} \mathrm{H}^{-1} \mathrm{H}$ COSY spectrum consisted of two broad singlets at $\delta_{\mathrm{H}} 4.19(1 \mathrm{H})$ and $4.68(1 \mathrm{H})$, one double doublet at $\delta 2.95(1 \mathrm{H}, J 16.7$ and $4.0 \mathrm{~Hz})$ and one broad doublet at $\delta 2.82(1 \mathrm{H}, J 16.7 \mathrm{~Hz})$. In the HSQC spectrum, cross-peaks were observed between the last two signals and the carbon signal at $\delta 29.5$ as well as between the two broad singlets at $\delta 4.19$ and 4.68 and the carbon signals at $\delta 67.1$ and 79.9, respectively. This information, along with the presence of the aforementioned hexasubstituted aromatic ring and the spin system III, which in turn showed correlations in the HSQC spectrum with the methine carbons at $\delta 119.3,116.4$ and 115.1, respectively, were in accordance with the presence of an epicatechin residue in the structure of $\mathbf{1}$ bearing alkyl side chains at carbons $\mathrm{C}-6$ and $\mathrm{C}-8$ of ring A. ${ }^{78}$ The remaining carbon resonances in the aliphatic region of the ${ }^{13} \mathrm{C}$ NMR and distortionless enhancement by polarization transfer (DEPT) spectra suggested two $\mathrm{C}_{8}$ carbon-containing chains, each composed of four $\mathrm{sp}^{3}$ methylenes in the region of $\delta 31.6$ to 39.7 , two sp ${ }^{3}$ methines, one being oxymethinic $(\delta 70.0 / 70.8$, $\delta$ 24.9), one tertiary methyl group $(\delta 28.5)$ and one $\mathrm{sp}^{3}$ quaternary carbon indicative of the presence of a hemiacetal functionality ( $\delta 98.8 / 98.9)$. An interesting feature of the ${ }^{13} \mathrm{C}$ NMR spectrum of $\mathbf{1}$ was the appearance of these sets of signals, which showed very similar chemical shifts and the same multiplicities in the DEPT spectrum, the same being observed for the signals ascribed to the carbons of the two remaining 1,2,4-trisubstituted aromatic rings as well as the signals of their corresponding hydrogens (the abovementioned spin systems I and II). This led to the assumption that $\mathbf{1}$ had identical groups, which formed two disjoint spin-systems, linked to ring A of the epicatechin unit. On the basis of correlations discernible from ${ }^{1} \mathrm{H}-{ }^{1} \mathrm{H}$ COSY, HSQC and HMBC experiments, they were characterized as being two glucosylated phenyloctanoid units, as shown in Figure 1. A cross-peak between the anomeric proton of the two glucosyl moieties at $\delta 4.64$ and the oxygenated carbon of the two trisubstituted aromatic rings at $\delta 145.9$ (attributed to C-12a) and $\delta 144.7$ (attributed to C-12b) in the HMBC spectrum revealed the linkage between these two groups. The HMBC connectivities between $\mathrm{H}-14 \mathrm{a}(\delta$ 6.57) and C-12a and between $\mathrm{H}-14 \mathrm{~b}(\delta 6.51)$ and $\mathrm{C}-12 \mathrm{~b}$ provided further support for these assignments. Likewise, the correlations between the carbon signals at $\delta 139.4$ $(\mathrm{C}-9 \mathrm{a})$ and $139.6(\mathrm{C}-9 \mathrm{~b})$ with the proton signals ascribed to, respectively, $\mathrm{H}-8 \mathrm{a}(\delta 2.46)$ and $\mathrm{H}-8 \mathrm{~b}(\delta 2.30$ and 2.57$)$ established the linkage between the aromatic rings and the benzylic methylene group of the two aliphatic eight-carbon chains. The signals of these methylene protons, in turn, were found to have long-range correlations with the signal of the corresponding vicinal carbons $(\mathrm{C}-7 \mathrm{a}$ and $\mathrm{C}-7 \mathrm{~b}, \delta$ 39.7). The remaining degrees of unsaturation suggested by the molecular formula of $\mathbf{1}$ indicated that the eight-carbon moieties must have one ring system each. This information, together with the above-mentioned structural fragments, and the evidence of substitution at C- 6 and C-8 positions of the epicatechin unit, were strongly indicative that the carbons of these alkyl side chains formed, along with C-6/C-8 and the oxygen atoms at C-5/C-7 positions of the epicatechin core, a six-membered hemiacetal bearing a methyl group bonded to the hemiacetal carbon. Accordingly, the attachment of C-1a/C-1b to C-6/C-8 of the epicatechin skeleton was deduced unambiguously from the correlations between $\mathrm{H}-1 \mathrm{a} / \mathrm{H}-1 \mathrm{~b}(\delta 3.40 / 3.42)$ and $\mathrm{C}-6 / \mathrm{C}-8(\delta 105.3 / 105.6)$ in the HMBC spectrum. Furthermore, the cross-peaks between the methylene carbon signals at $\delta 35.6 / 35.4(\mathrm{C}-2 \mathrm{a} / \mathrm{C}-$ $2 \mathrm{~b}$ ) and the proton signals of $\mathrm{H}-1 \mathrm{a}$ and $\mathrm{H}-1 \mathrm{~b}$, as well as between the hemiacetal carbon signals C-3a and C-3b at $\delta$ 98.9 and 98.8, respectively, and the methyl singlets at $\delta_{\mathrm{H}}$ $1.47 / 1.52$ ( $\mathrm{H}-4 \mathrm{a}$ and $\mathrm{H}-4 \mathrm{~b}$, respectively) corroborated the aforementioned suggestion. The methylene carbon signals observed at $\delta 36.8$ and those assignable to hydroxylbearing methine carbons at $\delta 70.8 / 70.0$ accounted for the remaining carbons of the side chains, namely $\mathrm{C}-5 \mathrm{a} / \mathrm{C}-5 \mathrm{~b}$ and C-6a/C-6b, respectively, which showed connectivities in the HSQC spectrum with the signals attributed to $\mathrm{H}-5 \mathrm{a} / \mathrm{H}-5 \mathrm{~b}(\delta 1.60 ; 1.88 / 1.64 ; 1.53)$ and $\mathrm{H}-6 \mathrm{a} / \mathrm{H}-6 \mathrm{~b}(\delta$ $3.53 / 3.57$ ), respectively. Cross-peaks between $\mathrm{H}-6 \mathrm{a} / \mathrm{H}-6 \mathrm{~b}$ $(\delta 3.53 / 3.57)$ and $\mathrm{H}-7 \mathrm{a} / \mathrm{H}-7 \mathrm{~b}(\delta 1.47)$ in the ${ }^{1} \mathrm{H}-{ }^{1} \mathrm{H}$ COSY spectrum along with two-bond $\mathrm{C}-\mathrm{H}$ correlations observed between $\mathrm{H}-1 \mathrm{a} / \mathrm{H}-1 \mathrm{~b}(\delta 3.40 / 3.42)$ and $\mathrm{C}-5 \mathrm{a} / \mathrm{C}-5 \mathrm{~b}(\delta 36.8)$ in the $\mathrm{HMBC}$ spectrum were in accordance with these assignments. The stereochemistry at C-6a and C-6b could 

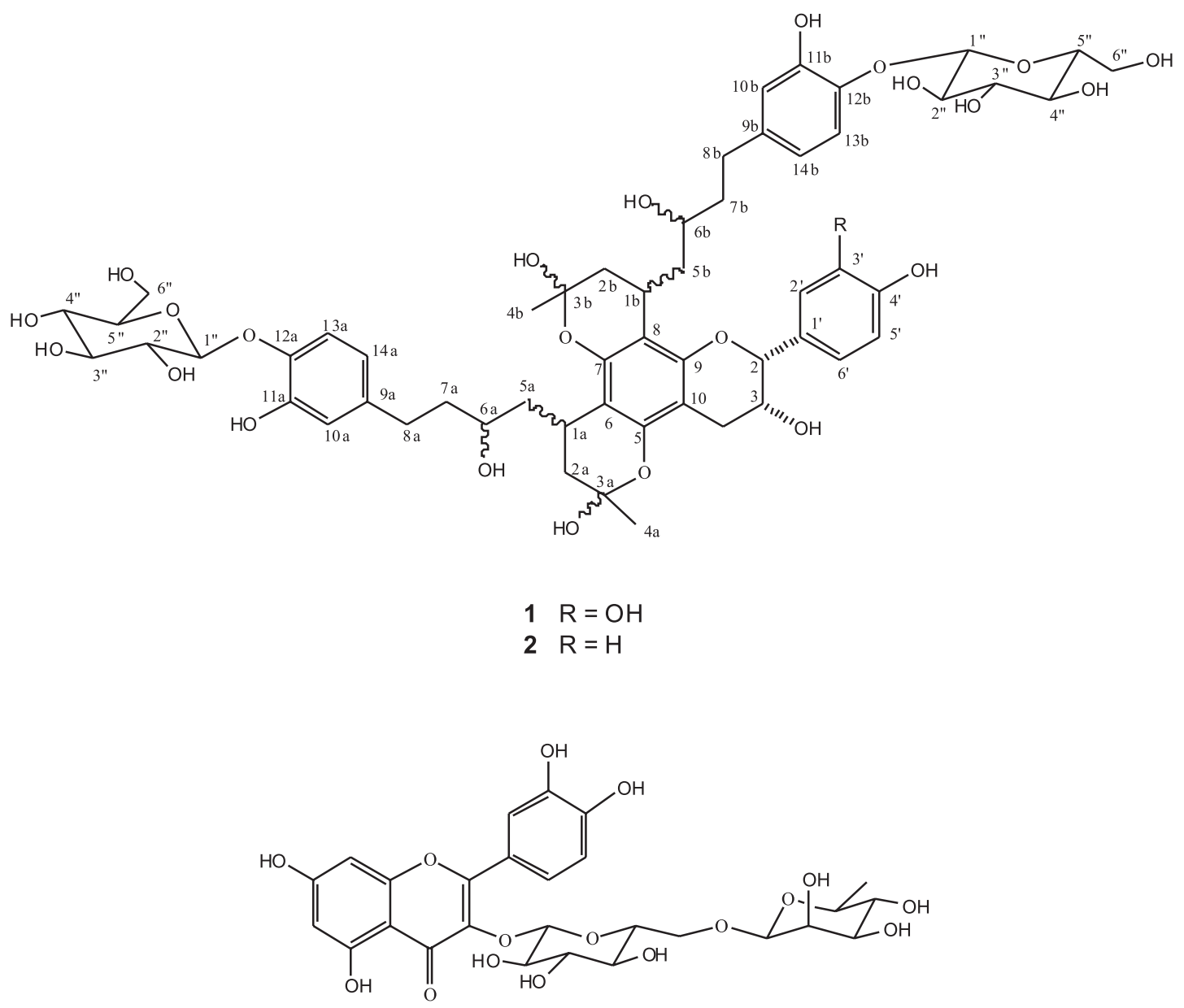

Figure 1. Structures of compounds 1-3 isolated from M. pubiflora.

not be elucidated while the stereochemical relationships of $\mathrm{H}-1 \mathrm{a} / \mathrm{H}-1 \mathrm{~b}$ with the methyl groups $\mathrm{C}-4 \mathrm{a} / \mathrm{C}-4 \mathrm{~b}$ were determined to be syn, as revealed by analysis of the nuclear Overhauser enhancement spectroscopy (NOESY) spectrum. Further evidence of structure $\mathbf{1}$ was given by additional two- and three-bond correlations discernible in the HMBC spectrum (Table 1).

In summary, all the spectral data provided the basis to determine the structure $\mathbf{1}$ for mascagnin $\mathrm{A}$, an unusual epicatechin derivative, which has not been previously reported. Compound $\mathbf{2}$, to which was assigned the trivial name mascagnin B, displayed a quasi-molecular ion peak at $m / z 1097.3313$ [M-H] $^{-}$in the HRESIMS spectrum, which was sixteen mass units lower than that of $\mathbf{1}$ and in agreement with the molecular formula $\mathrm{C}_{55} \mathrm{H}_{70} \mathrm{O}_{23}$. The ${ }^{1} \mathrm{H}$ and ${ }^{13} \mathrm{C}$ NMR spectra of $\mathbf{2}$ are closely comparable to those of 1 (Table 2). However, the signals of ring B of the epicatechin moiety were not present, suggesting that $\mathbf{2}$ differed from $\mathbf{1}$ only in the nature of the flavan-3-ol nucleus. Accordingly, the presence of a typical pair of
AA'BB' doublets at $\delta_{\mathrm{H}} 7.32\left(2 \mathrm{H}, J 8.2 \mathrm{~Hz}, \mathrm{H}-2^{\prime}\right.$ ' and H-6') and $\delta_{\mathrm{H}} 6.80\left(2 \mathrm{H}, J 8.2 \mathrm{~Hz}, \mathrm{H}-3^{\prime}\right.$ and $\mathrm{H}-5$ ') was clearly indicative of a para-hydroxy substituted ring $\mathrm{B}$ in the structure of $\mathbf{2}$. This could also be deduced from the carbon resonances at $\delta_{\mathrm{C}} 131.8$ (C-1'), 128.9 (C-2',C-6'), 115.9 (C-3', C-5') and 157.9 (C-4') and from the connectivities observed between the proton and carbon signals of ring $B$ in the HSQC and HMBC spectra (Table 2). These data can be accounted for in $\mathbf{2}$ if the epicatechin nucleus of $\mathbf{1}$ is replaced by a flavan-3-ol moiety of the epiafzelechintype. The spectral data reported in the literature for epiafzelechin supported this assumption. ${ }^{79}$ The remaining ${ }^{1} \mathrm{H}$ and ${ }^{13} \mathrm{C}$ NMR assignments of mascagnin $\mathrm{B}$ were based on the information afforded by DEPT, HSQC and HMBC experiments and also by comparison with the data obtained for $\mathbf{1}$ (Table 2). Thus, the structure of $\mathbf{2}$, a novel epiafzelechin derivative, was established as that depicted in Figure 1.

The biogenetic origin of the phenyloctanoid residues found in the unique epicatechin and epiafzelechin 
Table 2. ${ }^{1} \mathrm{H}(300 \mathrm{MHz})$ and ${ }^{13} \mathrm{C}(75 \mathrm{MHz})$ spectral data of 2

\begin{tabular}{|c|c|c|c|c|c|c|c|}
\hline No & $\delta_{\mathrm{C}}^{\mathrm{a}}$ & $\delta_{\mathrm{H}}(\mathrm{J} \text { in Hz) })^{\mathrm{a}}$ & $\mathrm{HMBC}(\mathrm{H} \rightarrow \mathrm{C})$ & No & $\delta_{\mathrm{C}}^{\mathrm{a}}$ & $\delta_{\mathrm{H}}{ }^{\mathrm{a}}$ & $\mathrm{HMBC}(\mathrm{H} \rightarrow \mathrm{C})$ \\
\hline 2 & 79.8 & $4.68 \mathrm{brs}$ & $\mathrm{C} 1^{\prime}, \mathrm{C} 2^{\prime} / 6^{\prime}$ & $12 \mathrm{a}$ & 144.9 & - & \\
\hline 3 & 67.2 & 4.25 brt (3.0) & $\mathrm{C} 10$ & $13 \mathrm{a}$ & 119.5 & $7.00 \mathrm{~d}(8.2)$ & C-9a, C-11a, C-12a \\
\hline 4 & 29.6 & $\begin{array}{l}2.88 \mathrm{dd}(17.0,4.5) \\
2.96 \mathrm{dd}(17.0,2.8)\end{array}$ & $\begin{array}{c}\text { C-5, C-9, C-10 } \\
\text { C-3, C-5, C-9, C-10 }\end{array}$ & $14 \mathrm{a}$ & 121.1 & $6.58 \mathrm{dd}(8.2,2.0)$ & $\mathrm{C}-10 \mathrm{a}, \mathrm{C}-12 \mathrm{a}$ \\
\hline 5 & 151.8 & - & & $1 \mathrm{~b}$ & 24.9 & $3.43 \mathrm{~m}$ & \\
\hline 6 & 106.5 & - & & $2 \mathrm{~b}$ & 35.6 & $\begin{array}{l}1.70 \mathrm{~m} \\
1.97 \mathrm{~m}\end{array}$ & $C-8, C-3 b$ \\
\hline 7 & 154.1 & - & & $3 b$ & 99.0 & - & \\
\hline 8 & 105.5 & - & & $4 \mathrm{~b}$ & 28.3 & $1.51 \mathrm{~s}$ & $C-2 b, C-3 b$ \\
\hline 9 & 151.1 & - & & $5 \mathrm{~b}$ & 36.8 & $\begin{array}{l}1.53 \mathrm{~m} \\
1.64 \mathrm{~m}\end{array}$ & $C-1 b, C-2 b, C-9 b$ \\
\hline 10 & 99.3 & - & & $6 \mathrm{~b}$ & 70.7 & $3.55 \mathrm{~m}$ & \\
\hline $1^{\prime}$ & 131.8 & - & & $7 \mathrm{~b}$ & 39.7 & $1.66-1.71 \mathrm{~m}$ & \\
\hline $2^{\prime} / 6^{\prime}$ & 128.9 & $7.32 \mathrm{~d}(8.2)$ & $\mathrm{C}-2, \mathrm{C}-3^{\prime} / 5^{\prime}, \mathrm{C}-4^{\prime}$ & $8 \mathrm{~b}$ & 32.0 & $2.41 \mathrm{~m}$ & \\
\hline $3^{\prime} / 5$ & 115.9 & $6.80 \mathrm{~d}(8.2)$ & $\mathrm{C}-1^{\prime}, \mathrm{C}-4^{\prime}$ & $9 b$ & 139.5 & - & \\
\hline $4^{\prime}$ & 157.9 & - & & $10 \mathrm{~b}$ & 117.2 & $6.61 \mathrm{~d}(2.0)$ & $C-8 b, C-11 b, C-12 b, C-14 b$ \\
\hline $1 \mathrm{a}$ & 25.0 & $3.43 \mathrm{~m}$ & $C-2 a, C-5 a$ & $11 \mathrm{~b}$ & 148.0 & - & \\
\hline $2 \mathrm{a}$ & 35.6 & $\begin{array}{l}1.70 \mathrm{~m} \\
1.97 \mathrm{~m}\end{array}$ & $\mathrm{C}-3 \mathrm{a}, \mathrm{C}-6$ & $12 \mathrm{~b}$ & 144.8 & - & \\
\hline $3 \mathrm{a}$ & 98.8 & - & & $13 b$ & 119.1 & $7.01 \mathrm{~d}(8.2)$ & $C-9 b, C-11 b, C-12 b$ \\
\hline $4 a$ & 28.4 & $1.54 \mathrm{~s}$ & $C-2 a, C-3 a$ & $14 \mathrm{~b}$ & 120.9 & $6.53 \mathrm{dd}(8.2,2.0)$ & $C-10 b, C-12 b$ \\
\hline $5 \mathrm{a}$ & 36.9 & $\begin{array}{l}1.60 \mathrm{~m} \\
1.88 \mathrm{~m}\end{array}$ & & $1 ”$ & $104.6 / 104.9$ & $4.64 / 4.65 \mathrm{~d}(7.5)$ & $C-12 a, C-12 b$ \\
\hline $6 a$ & 69.9 & $3.59 \mathrm{~m}$ & & $2 "$ & 74.9 & $3.43 \mathrm{~m}$ & \\
\hline $7 \mathrm{a}$ & 38.8 & $1.60-1.69 \mathrm{~m}$ & & $3 "$ & $78.1 / 78.2$ & $3.35 \mathrm{~m}$ & \\
\hline $8 a$ & 32.5 & $2.33-2.59 \mathrm{~m}$ & & $4 "$ & $71.3 / 71.4$ & $3.36 \mathrm{~m}$ & \\
\hline $9 \mathrm{a}$ & 139.7 & - & & $5 "$ & $77.5 / 77.6$ & $3.42 \mathrm{~m}$ & \\
\hline $10 \mathrm{a}$ & 117.4 & $6.64 \mathrm{~d}(2.0)$ & C-8a, C-12a, C-14a & $6 "$ & 62.5 & $\begin{array}{c}3.65 \mathrm{~m} \\
3.87 \mathrm{dd}(11.8,4.5)\end{array}$ & \\
\hline $11 \mathrm{a}$ & 148.3 & - & & & & & \\
\hline
\end{tabular}

${ }^{\mathrm{a}}$ Assignments of H/C 1a-14a may be interchanged with those of H/C 1b-14b.

derivatives $\mathbf{1}$ and $\mathbf{2}$ can be postulated as arising from chain

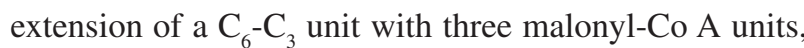
followed by hydrolysis and decarboxylation of the terminal thioester function of the polyketide moiety.

The ${ }^{1} \mathrm{H}$ and ${ }^{13} \mathrm{C}$ NMR spectral data of compound 3 (Figure 1) were found to be in good agreement with those of a di- $O$-glycosylflavonol of the rutinoside-type which was identified as the known quercetin-3- $O-\alpha$-L-rhamnopyranosyl$(1 \rightarrow 6)$ - $\beta$-D-glucopyranoside (rutin). ${ }^{5,10}$

In spite of the wide occurrence of epicatechin and epiafzelechin as plant constituents, the isolation of flavan3-ol derivatives bearing glucosylated phenyloctanoid units from M. pubiflora in the present work is noteworthy, since only two records are found in the literature on the chemical constituents of members of the genus Mascagnia: the aforementioned preliminary chemical study of $M$. pubiflora $^{4}$ and the reported isolation of two naphtho- $\gamma$ pyrone glycosides from M. rigida. ${ }^{11}$

\section{Experimental}

\section{General experimental procedures}

Optical rotations were determined on a Perkin Elmer 341 polarimeter ( $N a$ filter, $\lambda=589 \mathrm{~nm}$ ). Infrared (IR) spectra were recorded as $\mathrm{KBr}$ pellets on a Bomem-Hartmann \& Braun FT IR spectrometer. ${ }^{1} \mathrm{H}$ and ${ }^{13} \mathrm{C}$ 1D and 2D NMR spectra were obtained in $\mathrm{CD}_{3} \mathrm{OD}$ on Bruker DPX-300 and Bruker DRX 400 spectrometers operating at $300.13 \mathrm{MHz}$ $\left({ }^{1} \mathrm{H}\right) / 75.47 \mathrm{MHz}\left({ }^{13} \mathrm{C}\right)$ and $400.35 \mathrm{MHz}\left({ }^{1} \mathrm{H}\right) / 100.10 \mathrm{MHz}$ $\left({ }^{13} \mathrm{C}\right)$, respectively. Standard pulse sequences were used for homo- and heteronuclear correlation experiments. HRESIMS spectra were acquired in negative ion mode on an UltrOTOF-Q instrument (Bruker Daltonics). Column chromatography procedures were performed on silica gel 60 RP-18 (230-400 mesh) and Sephadex LH-20. Reversed phase semi-preparative HPLC separations were performed 
with a Shimadzu LC-6AD pump, using a RP-18, $21.6 \mathrm{x}$ $250 \mathrm{~mm}, 5 \mu \mathrm{m}$ particle size, Phenomenex Luna column, with a flow rate of $14 \mathrm{~mL} \mathrm{~min}^{-1}$, monitoring at $254 \mathrm{~nm}$ with Shimadzu Detector.

\section{Plant material}

The aerial parts of $M$. pubiflora were collected in Aquidauana, Mato Grosso do Sul, Brazil, in August 2006. The plant material was identified by Dr. Arnildo Pott from the Empresa Brasileira de Pesquisa Agropecuária, EMBRAPA-CPAO, Campo Grande, MS, Brazil, where a voucher specimen (No. 5218) is deposited.

\section{Extraction and isolation of chemical constituents}

Dried and ground aerial parts of M. pubiflora $(466.0 \mathrm{~g})$ were extracted at room temperature with EtOH. After concentration in vacuo, the residue obtained from the EtOH extract was suspended in 1:1 MeOH- $\mathrm{H}_{2} \mathrm{O}$ and subsequently partitioned with $\mathrm{CHCl}_{3}$ and EtOAc to give the corresponding $\mathrm{CHCl}_{3}(19.6 \mathrm{~g})$ and EtOAc $(14.5 \mathrm{~g})$ phases. Part of the EtOAc soluble portion $(5.0 \mathrm{~g})$ was fractionated on a RP-18 silica gel column eluted successively with stepwise gradients of $\mathrm{H}_{2} \mathrm{O}-\mathrm{MeOH}$ (9.5:0.5, 4:1, 7:3, 3:2, 2:3, 1:4 and $\mathrm{MeOH})$ to yield seven fractions $(\mathrm{A} \rightarrow \mathrm{G})$. Fraction $\mathrm{C}\left(667.4 \mathrm{mg}, 7: 3 \mathrm{H}_{2} \mathrm{O}-\mathrm{MeOH}\right)$ was further chromatographed on a Sephadex LH-20 column using 3:2 EtOAc-MeOH as eluent to give two hundred and fifty fractions of $10 \mathrm{~mL}$ each. Fractions were grouped on the basis of their TLC profiles into twenty-two fractions $(\mathrm{F} 1 \rightarrow \mathrm{F} 22)$. Compound $\mathbf{3}(14.5 \mathrm{mg})$ was obtained from F16 (64.8 mg), after semi-preparative HPLC (1.5:8.5 $\left.\mathrm{CH}_{3} \mathrm{CN}-\mathrm{H}_{2} \mathrm{O}\right)$. A portion $(200.0 \mathrm{mg})$ of fraction $\mathrm{D}\left(434.9 \mathrm{mg}, 3: 2 \mathrm{H}_{2} \mathrm{O}-\mathrm{MeOH}\right)$ was further purified by semi-preparative HPLC $\left(1: 4 \mathrm{CH}_{3} \mathrm{CN}-\mathrm{H}_{2} \mathrm{O}\right)$ to yield $1(30.2 \mathrm{mg})$ and $\mathbf{2}(8.5 \mathrm{mg})$.

\section{Mascagnin A (1)}

Amorphous powder; $[\alpha]_{\mathrm{D}}^{23}:+11.43^{\circ}(c 0.17, \mathrm{MeOH})$; IR (KBr) $v_{\text {max }} / \mathrm{cm}^{-1}: 3410,2935,1617,1510,1197,1123$, 1072; ${ }^{1} \mathrm{H}$ and ${ }^{13} \mathrm{C}$ NMR data: see Table 1; HRESIMS $\mathrm{m} / \mathrm{z}$ $1113.3706[\mathrm{M}-\mathrm{H}]^{-}$(calcd for $\left.\mathrm{C}_{55} \mathrm{H}_{69} \mathrm{O}_{24}, 1113.4177\right)$.

\section{Mascagnin B (2)}

Amorphous powder; $[\alpha]_{\mathrm{D}}^{23}:+12.32^{\circ}(c 0.28, \mathrm{MeOH})$; IR $(\mathrm{KBr}) v_{\max } / \mathrm{cm}^{-1}: 3421,2932,1614,1506,1124,1073 ;{ }^{1} \mathrm{H}$ and ${ }^{13} \mathrm{C}$ NMR data: see Table 2; HRESIMS $\mathrm{m} / \mathrm{z} 1097.3313$ $[\mathrm{M}-\mathrm{H}]^{-}$(calcd. for $\mathrm{C}_{55} \mathrm{H}_{69} \mathrm{O}_{23}, 1097.4228$ ).

\section{Acknowledgements}

The authors are grateful to FUNDECT-MS and CPq-PROPP-UFMS for their financial support and to FUNDECT-MS and the CNPq for scholarships. Dr. Arnildo Pott (EMBRAPA-CPAO, Campo Grande, MS, Brazil, present address CGMS Herbarium, Universidade Federal de Mato Grosso do Sul, Campo Grande, MS, Brazil) is acknowledged for his assistance in the identification of the plant material. Thanks are also due to Dr. Norberto P. Lopes (Faculdade de Ciências Farmacêuticas, USP, Ribeirão Preto, Brazil) for the HRESIMS measurements.

\section{Supplementary Information}

${ }^{1} \mathrm{H} \mathrm{NMR},{ }^{13} \mathrm{C} \mathrm{NMR},{ }^{1} \mathrm{H}-{ }^{1} \mathrm{H}$ COSY, HSQC, HMBC and/ or HRESIMS spectra of compounds 1-3 are available free of charge at http://jbcs.org.br, as PDF file.

\section{References}

1. Riet-Correa, F.; Medeiros, R. M. T.; Pesq. Vet. Bras. 2001, 21, 38.

2. Tokarnia, C. H.; Döbereiner, J.; Peixoto, P. V.; Toxicon 2002, 40, 1635.

3. Tokarnia, C. H.; Döbereiner, J.; Pesq. Agropec. Bras. 1973, 8, 61; Afonso, E.; Pott, A.; Plantas no Pantanal Tóxicas para Bovinos, $5^{\text {a }}$ ed., EMBRAPA: Brasília, 2001.

4. Saad, A. D.; Andrade, S. O.; Aguiar, A. A.; An. Acad. Bras. Ciênc. 1970, 42 (Supl.), 235.

5. Agrawal, P. K.; Thakur, R. S.; Bansal, M. C. In Carbon-13 NMR of Flavonoids; Agrawal P. K., ed.; Elsevier: Amsterdam, 1989, ch. 6 .

6. Agrawal, P. K.; Phytochemistry 1992, 31, 3307.

7. Agrawal, P. K.; Thakur, R. S.; Bansal, M. C. In Carbon-13 NMR of Flavonoids; Agrawal P. K., ed. Elsevier: Amsterdam, 1989, ch. 8 .

8. Abe, Y.; Shoji, T.; Kawahara, N; Kamakura, H., Kanda, T.; Goda, Y.; Tetrahedron Lett. 2008, 49, 6413.

9. Kashiwada, Y.; Morita, M.; Nonaka, G.; Nishioka, I.; Chem. Pharm. Bull. 1990, 38, 856.

10. Beck, M. A.; Häberlein, H.; Phytochemistry 1999, 50, 329.

11. Nascimento, M. S.; Habermehl, G. G.; Fitoterapia 1995, 66, 539.

Received: November 12, 2008 Web Release Date: April 17, 2009

FAPESP helped in meeting the publication costs of this article. 
Two Unusual Epicatechin and Epiafzelechin Derivatives from Mascagnia pubiflora, a Plant Toxic to Cattle

Walmir S. Garcez, ${ }^{*, a}$ Fernanda R. Garcez, ${ }^{a}$ Deizeluci de F. P. Zanella, ${ }^{a, b}$ Lidilhone Hamerski, ${ }^{a}$ Antonio G. Ferreira, ${ }^{c}$ Andersson Barison ${ }^{c}$ and Alfredo R. Abot ${ }^{b}$

${ }^{a}$ Departamento de Química Universidade Federal de Mato Grosso do Sul, 79070-900 Campo Grande-MS, Brazil

${ }^{b}$ Universidade Estadual de Mato Grosso do Sul, Unidade Universitária de Aquidauana, 79200-000 Aquidauana-MS, Brazil

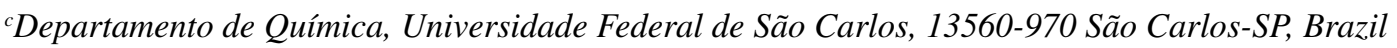

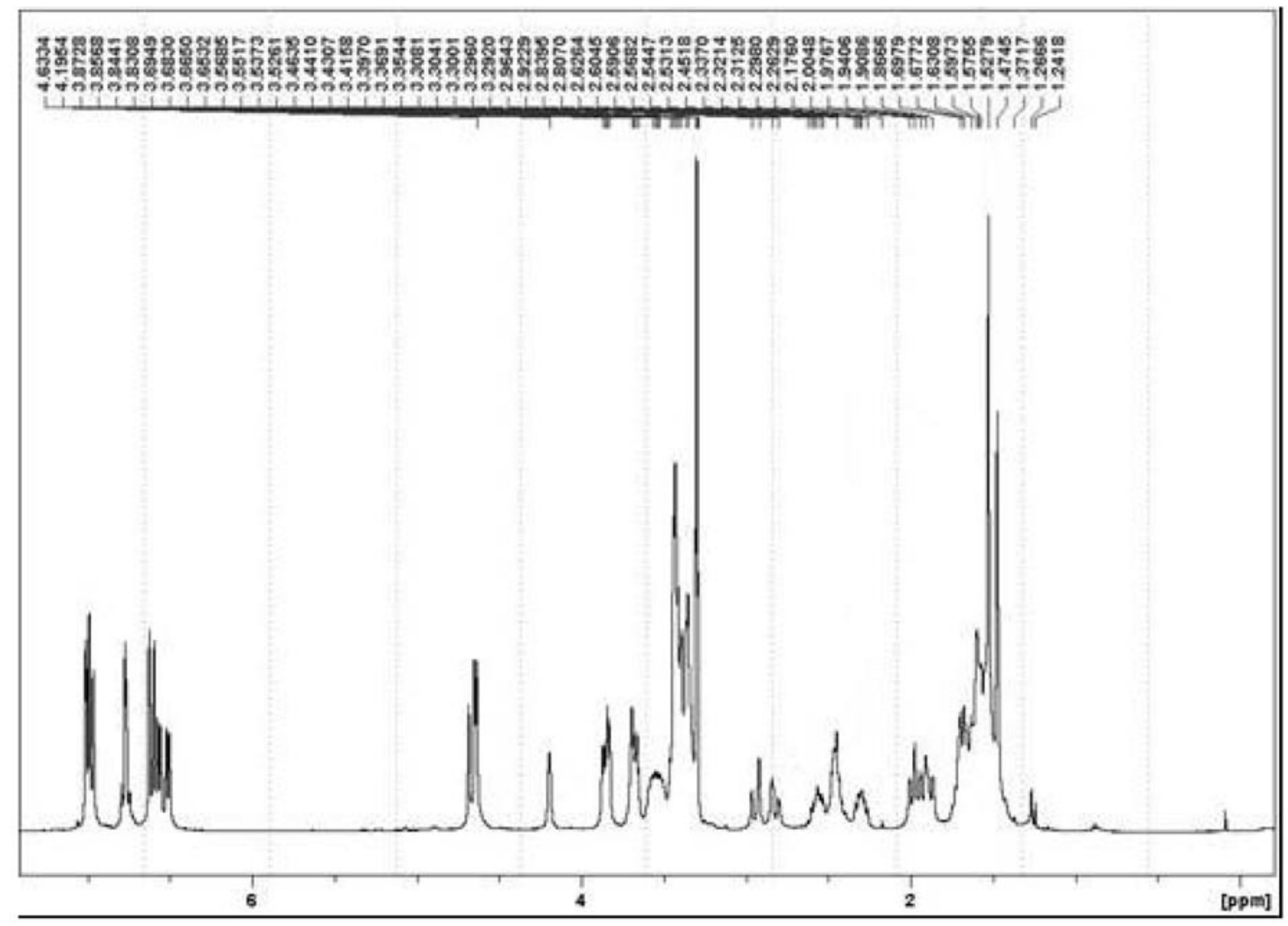

Figure S1. ${ }^{1} \mathrm{H}$ NMR spectrum (400 MHz, $\mathrm{CD}_{3} \mathrm{OD}$ ) of compound $\mathbf{1}$. 


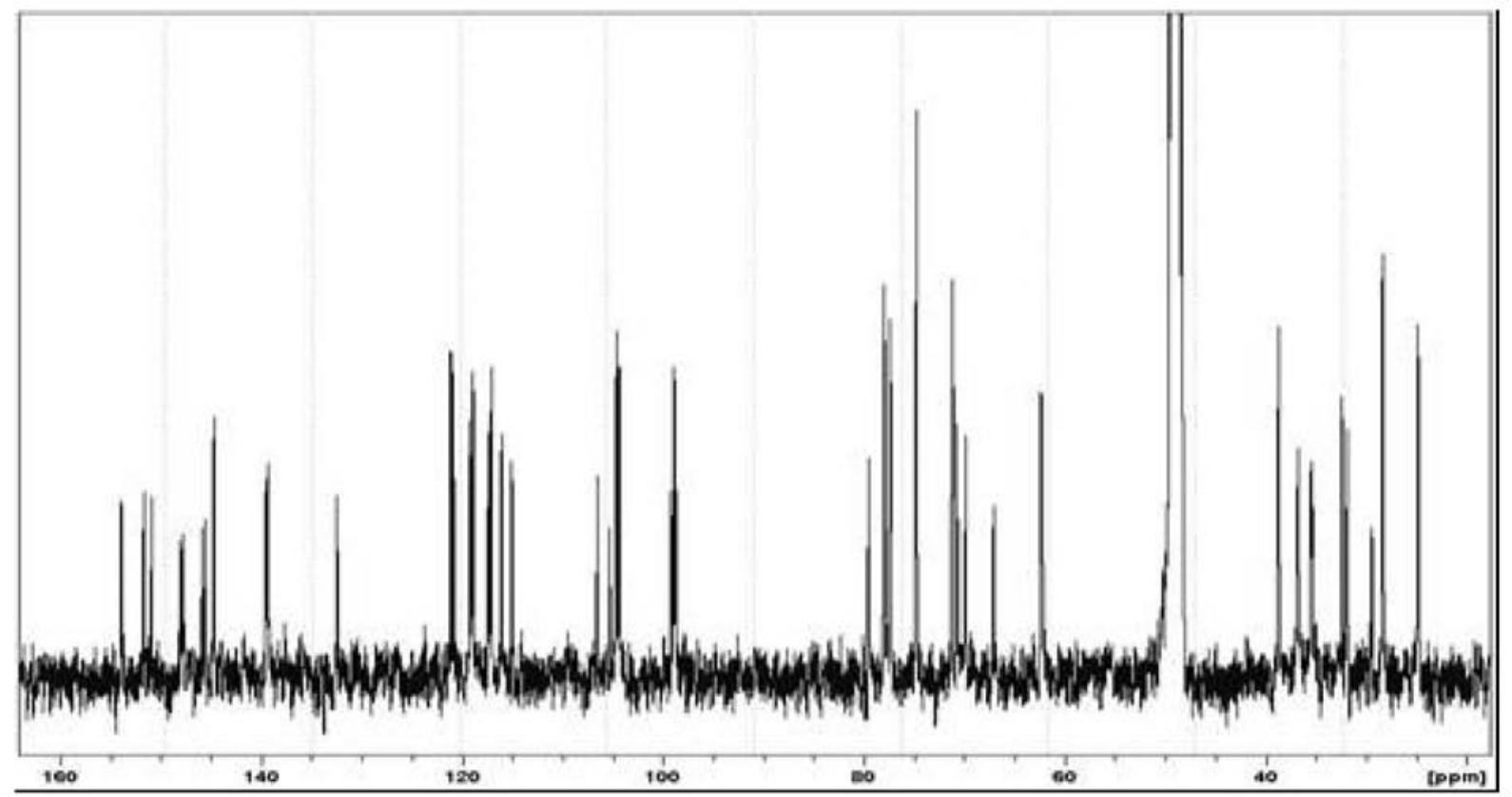

Figure S2. ${ }^{13} \mathrm{C}$ NMR spectrum $\left(100 \mathrm{MHz}, \mathrm{CD}_{3} \mathrm{OD}\right)$ of compound 1. 

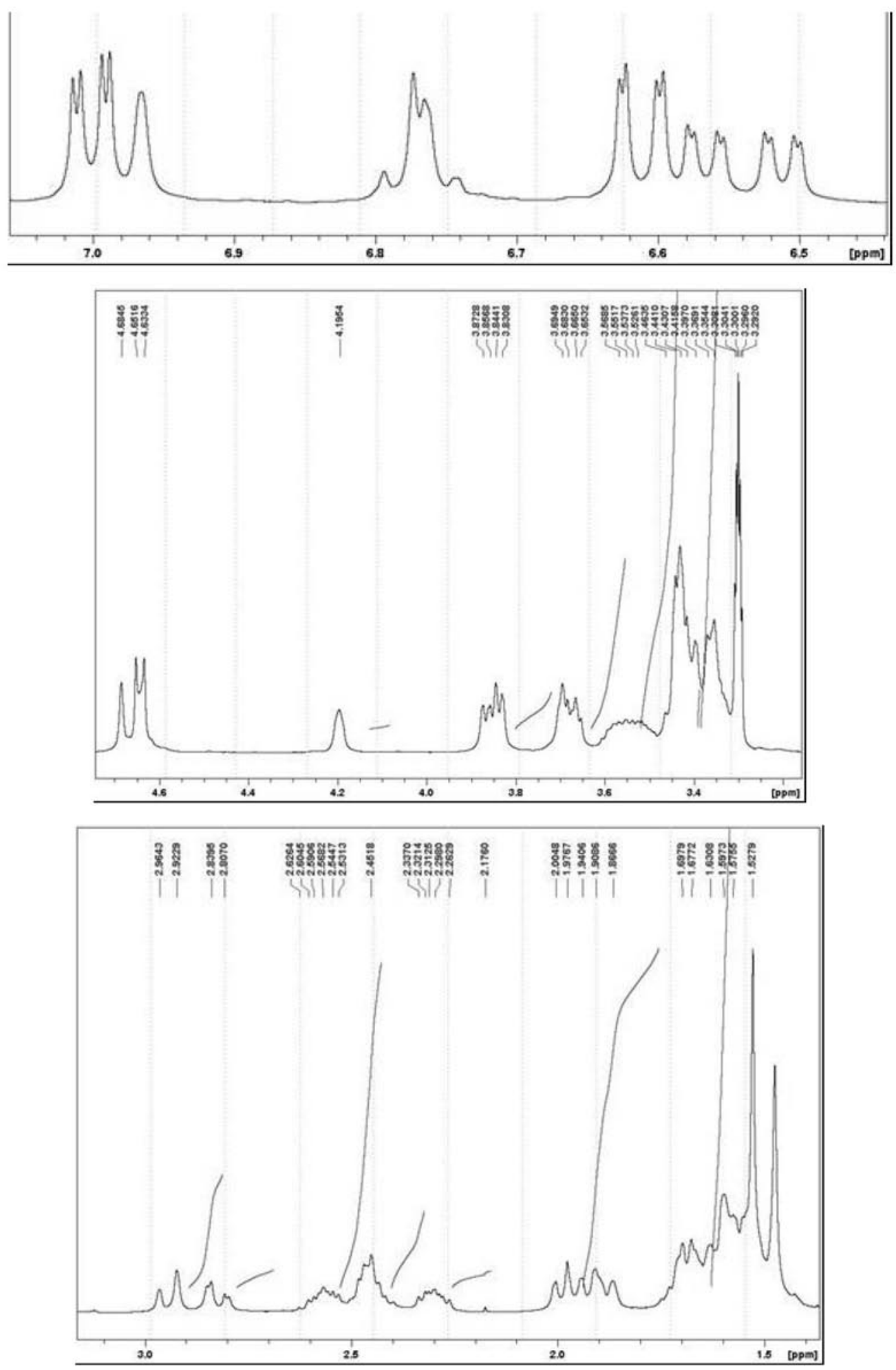

Figure S3. ${ }^{1} \mathrm{H}$ NMR spectrum (400 MHz, $\mathrm{CD}_{3} \mathrm{OD}$ ) of compound 1 (expansions). 

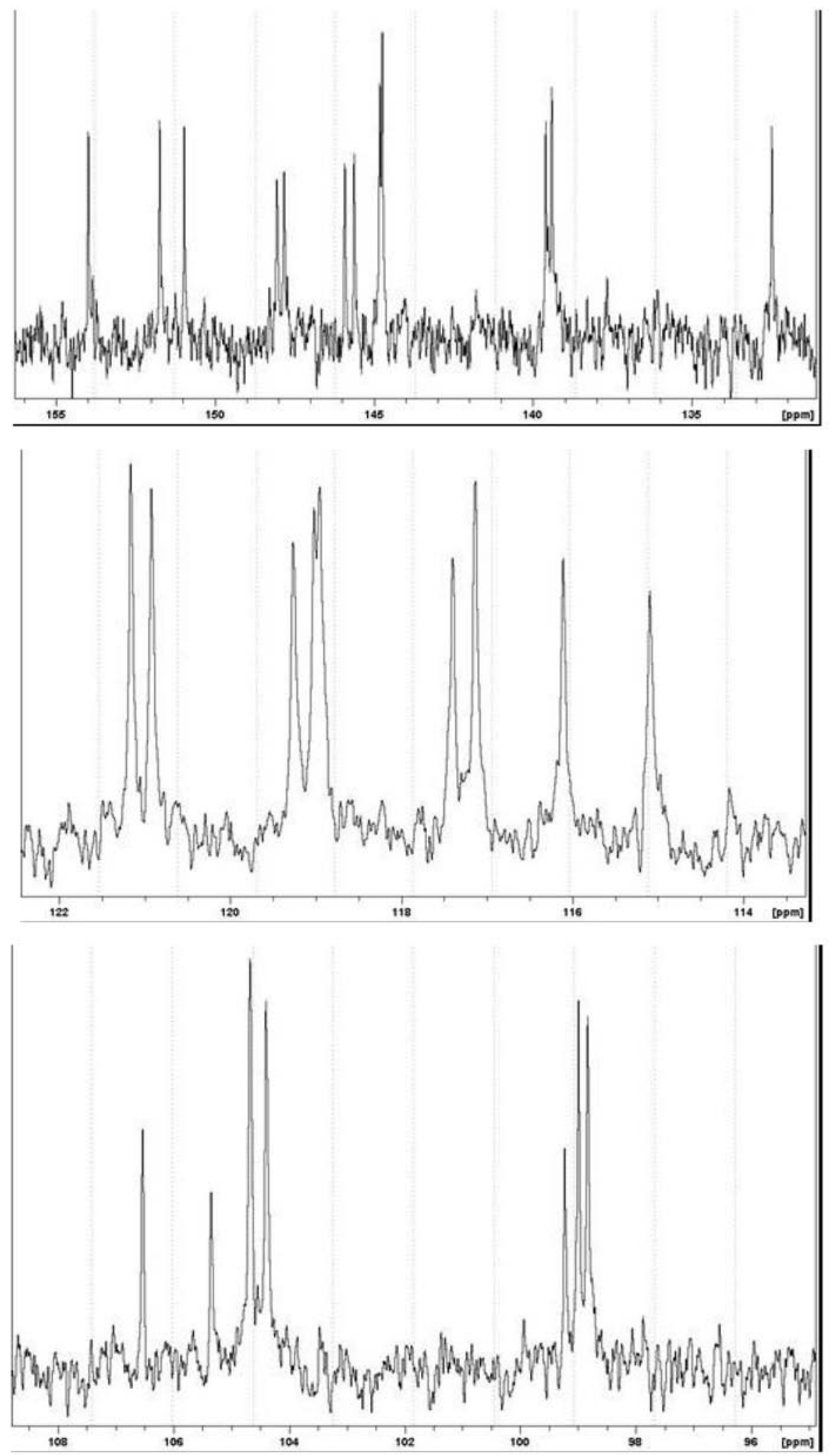

Figure S4. ${ }^{13} \mathrm{C}$ NMR spectrum $\left(100 \mathrm{MHz}, \mathrm{CD}_{3} \mathrm{OD}\right)$ of compound $\mathbf{1}$ (expansions). 


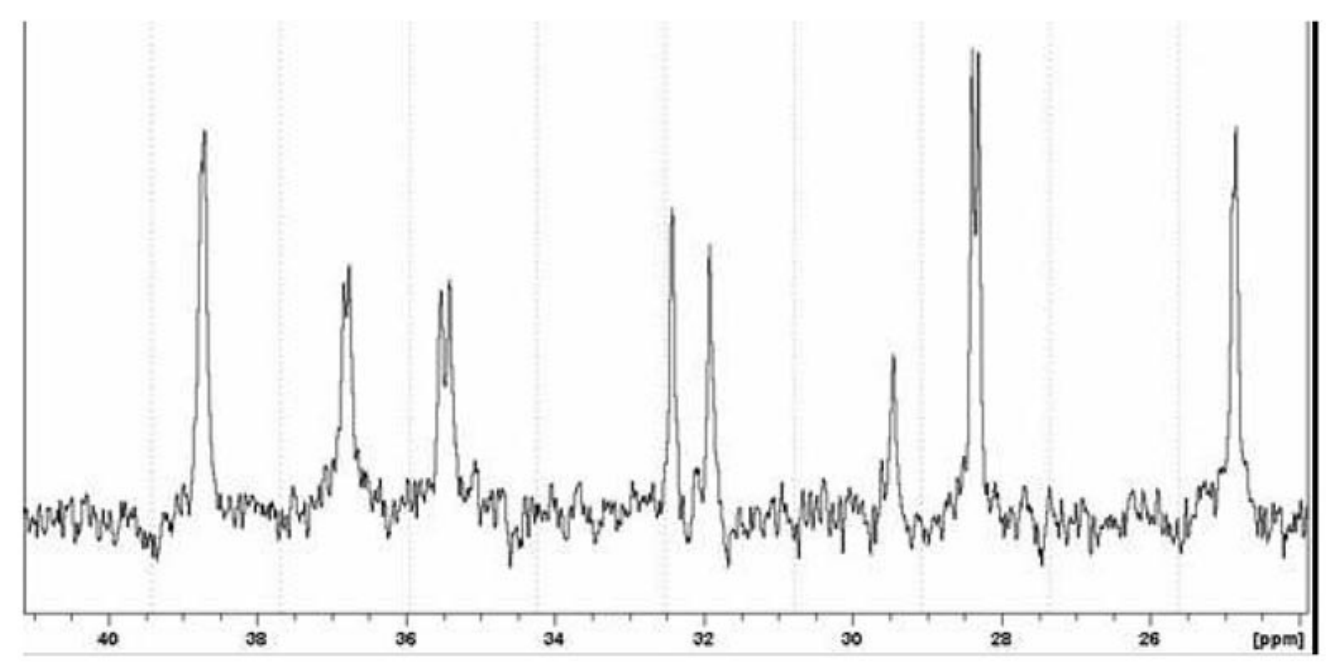

Figure S5. ${ }^{13} \mathrm{C}$ NMR spectrum ( $100 \mathrm{MHz}, \mathrm{CD}_{3} \mathrm{OD}$ ) of compound $\mathbf{1}$ (expansion).

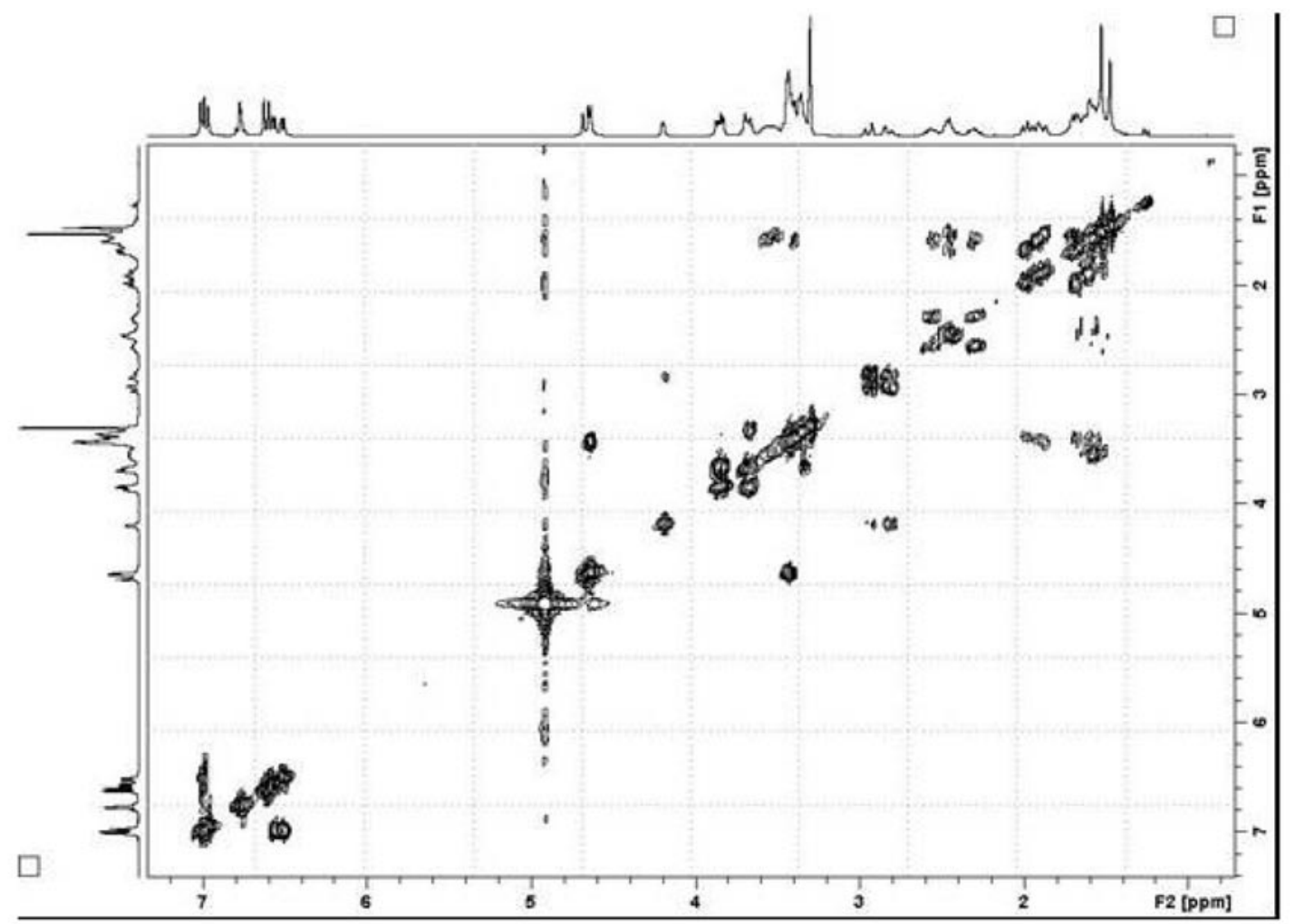

Figure S6. ${ }^{1} \mathrm{H}-{ }^{1} \mathrm{H}$ COSY spectrum $\left(\mathrm{CD}_{3} \mathrm{OD}\right)$ of compound $\mathbf{1}$. 


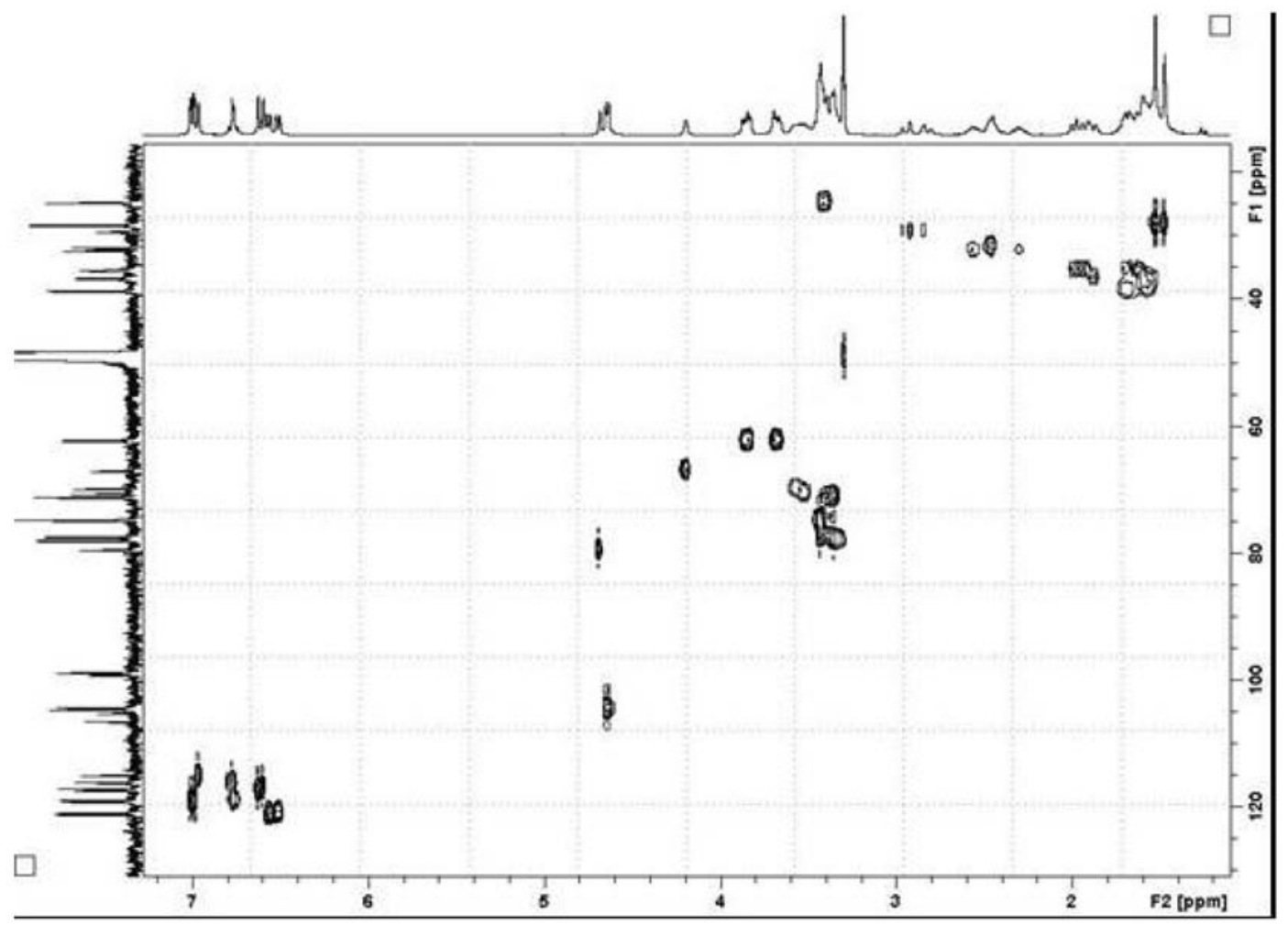

Figure S7. HSQC spectrum $\left(\mathrm{CD}_{3} \mathrm{OD}\right)$ of compound $\mathbf{1}$.

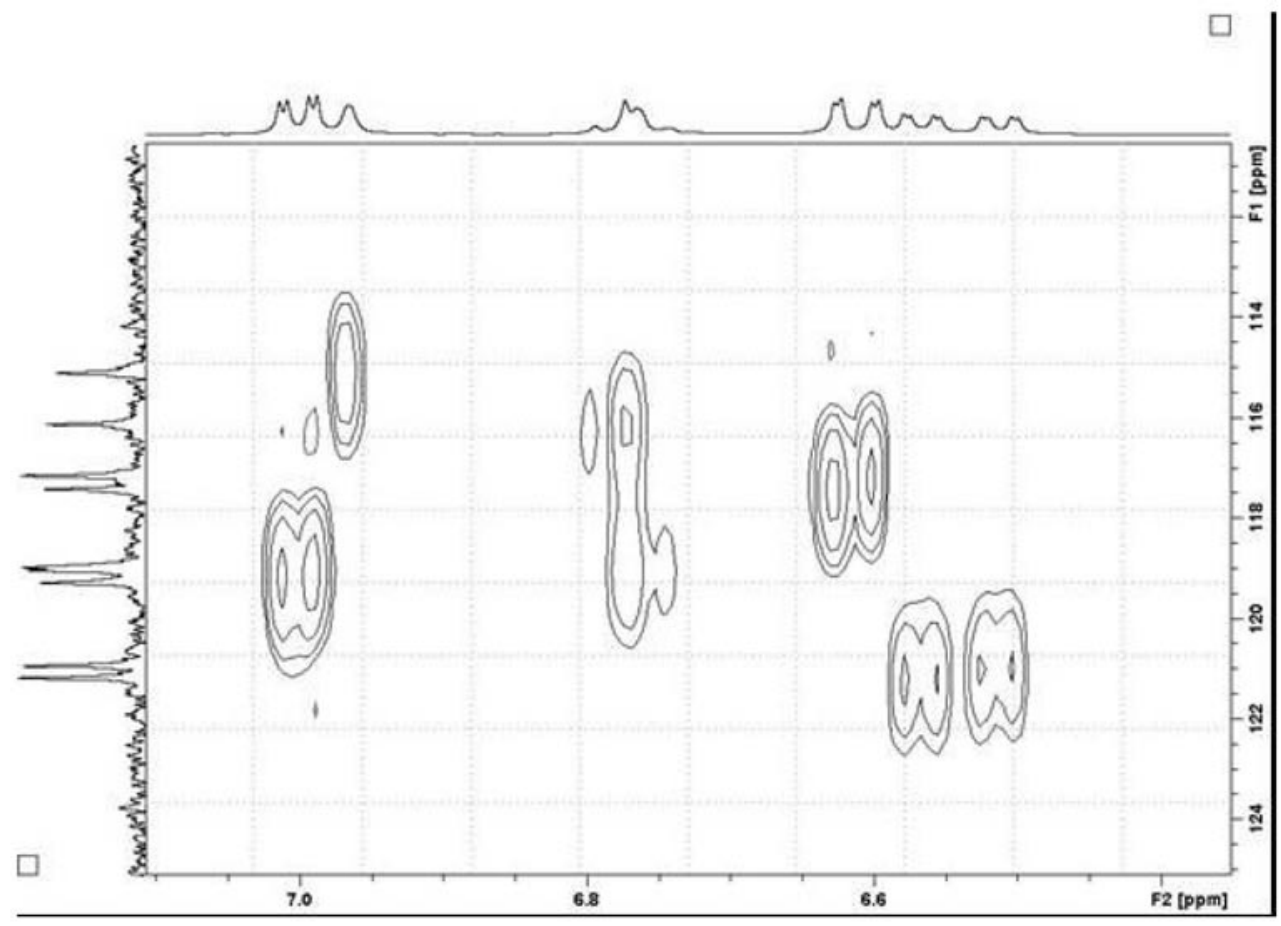

Figure S8. HSQC spectrum of compound 1 (expansion). 


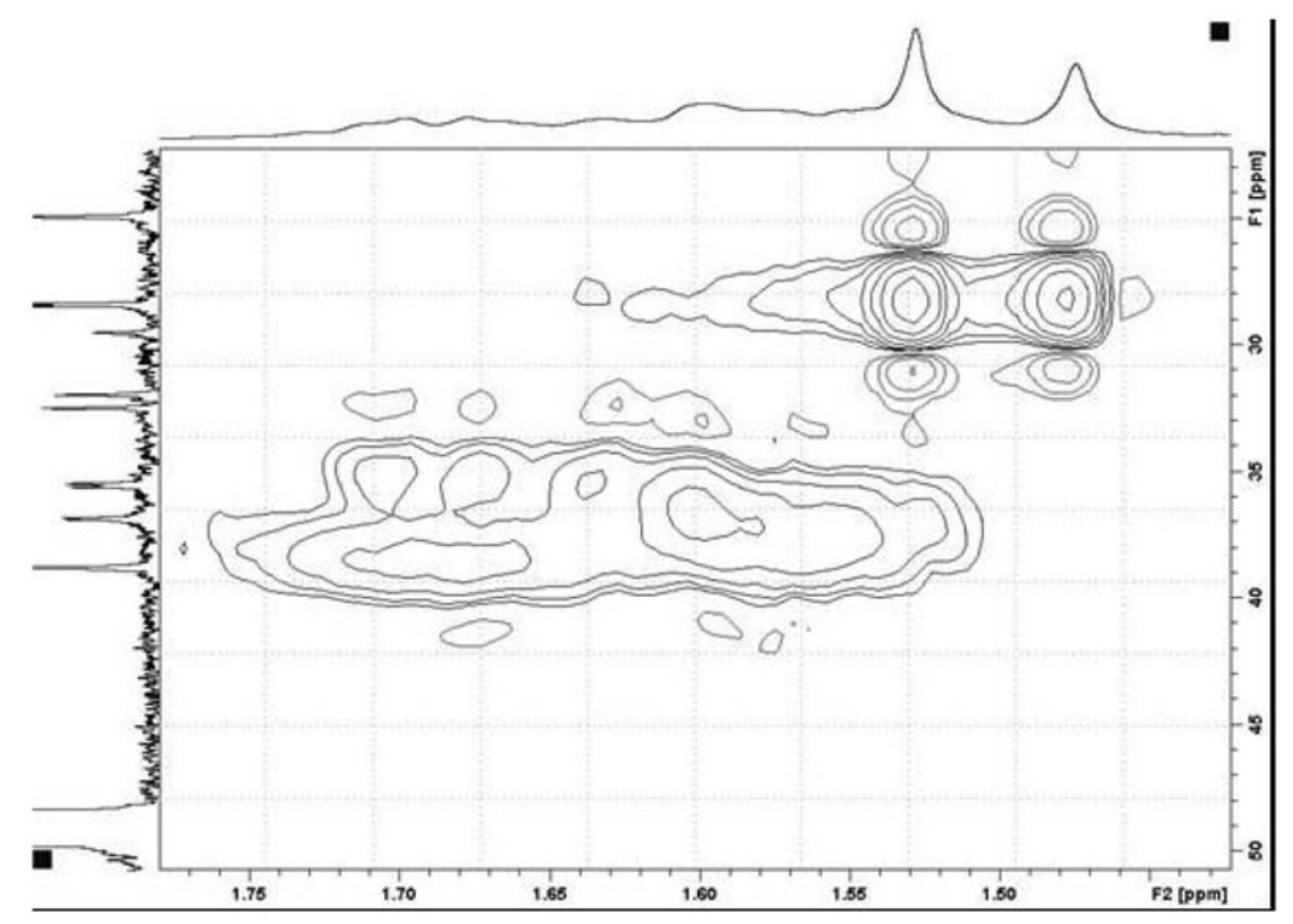

Figure S9. HSQC spectrum of compound 1 (expansion).

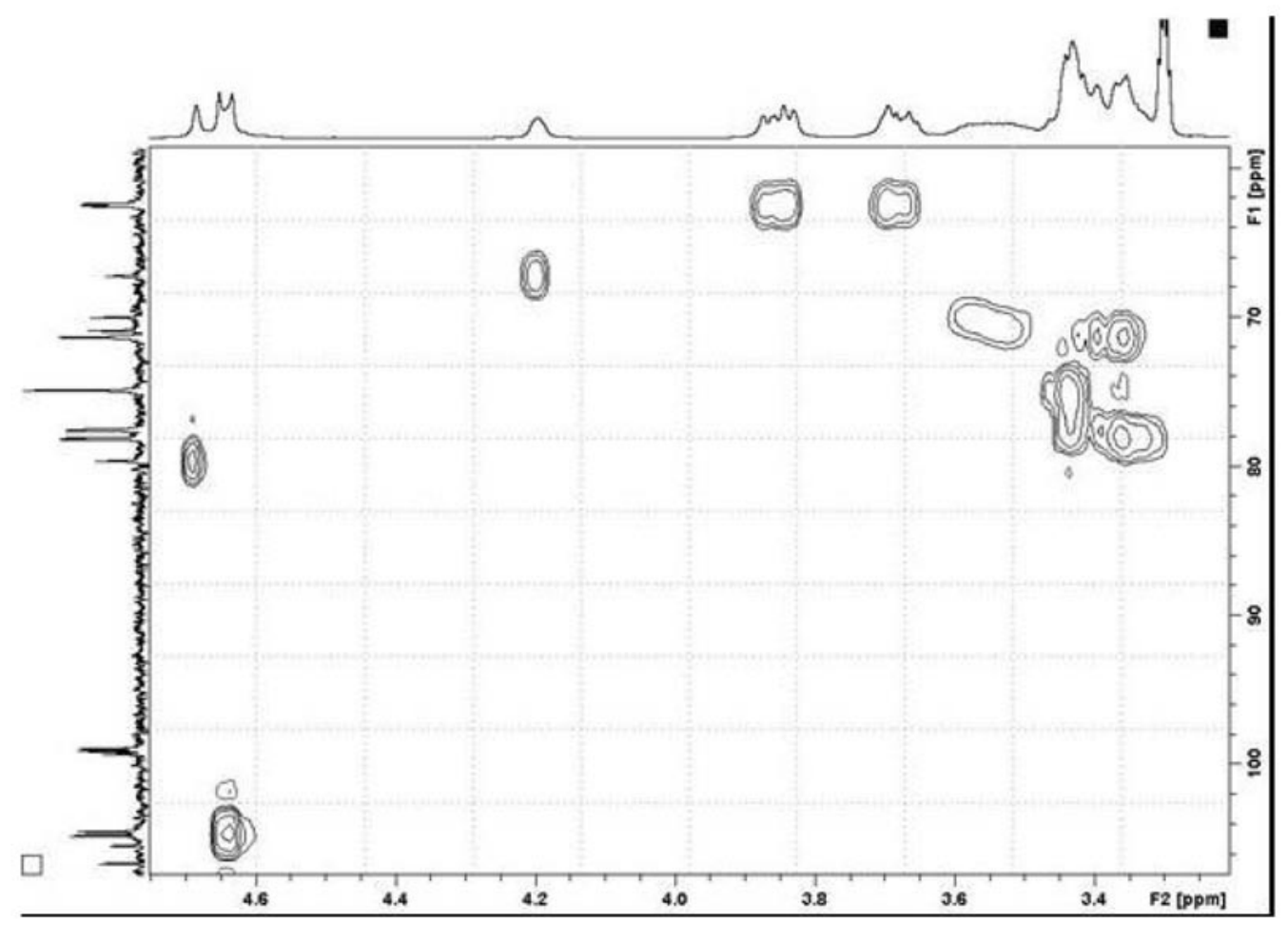

Figure S10. HSQC spectrum of compound 1 (expansion). 


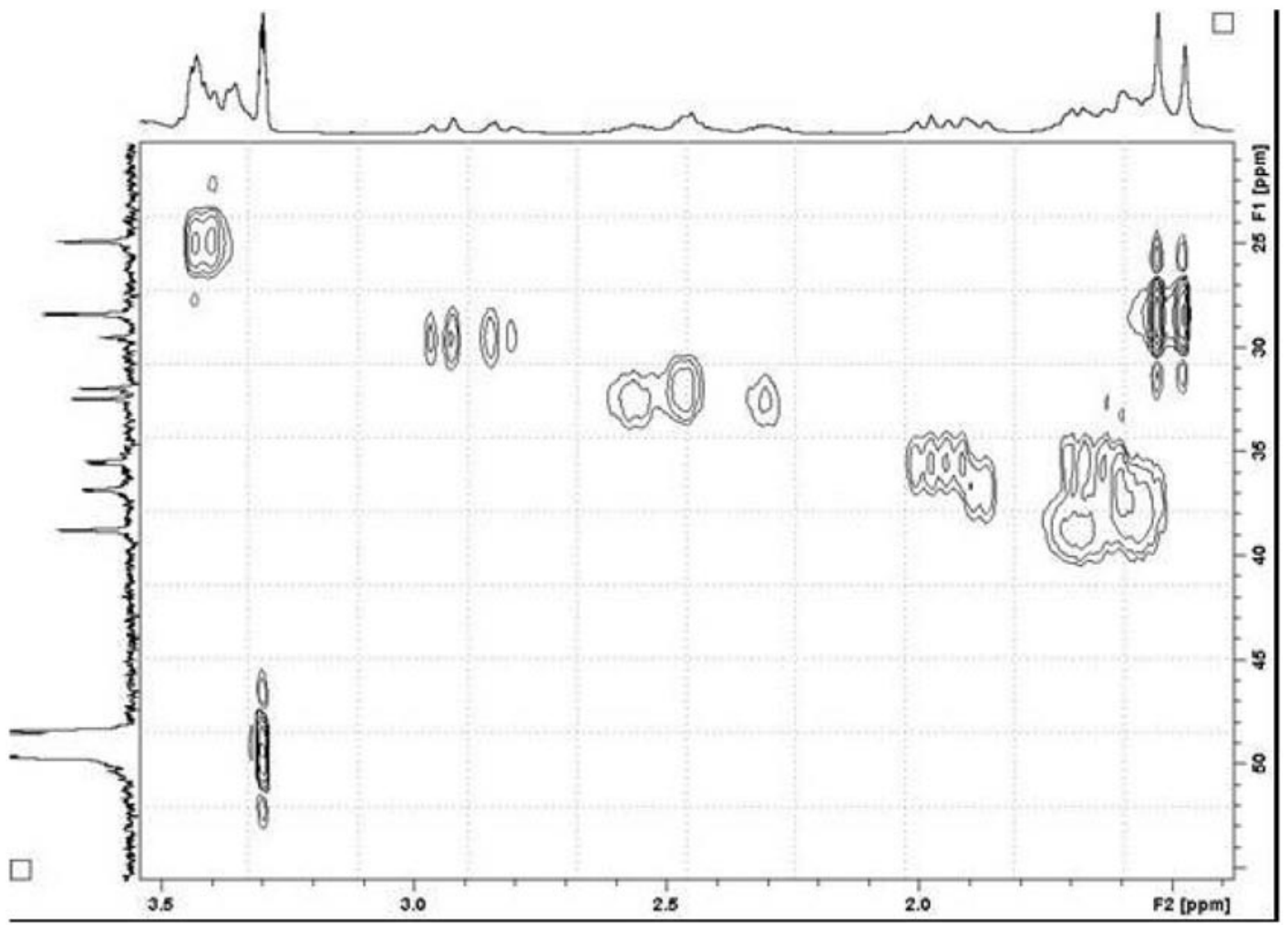

Figure S11. HSQC spectrum of compound 1 (expansion).

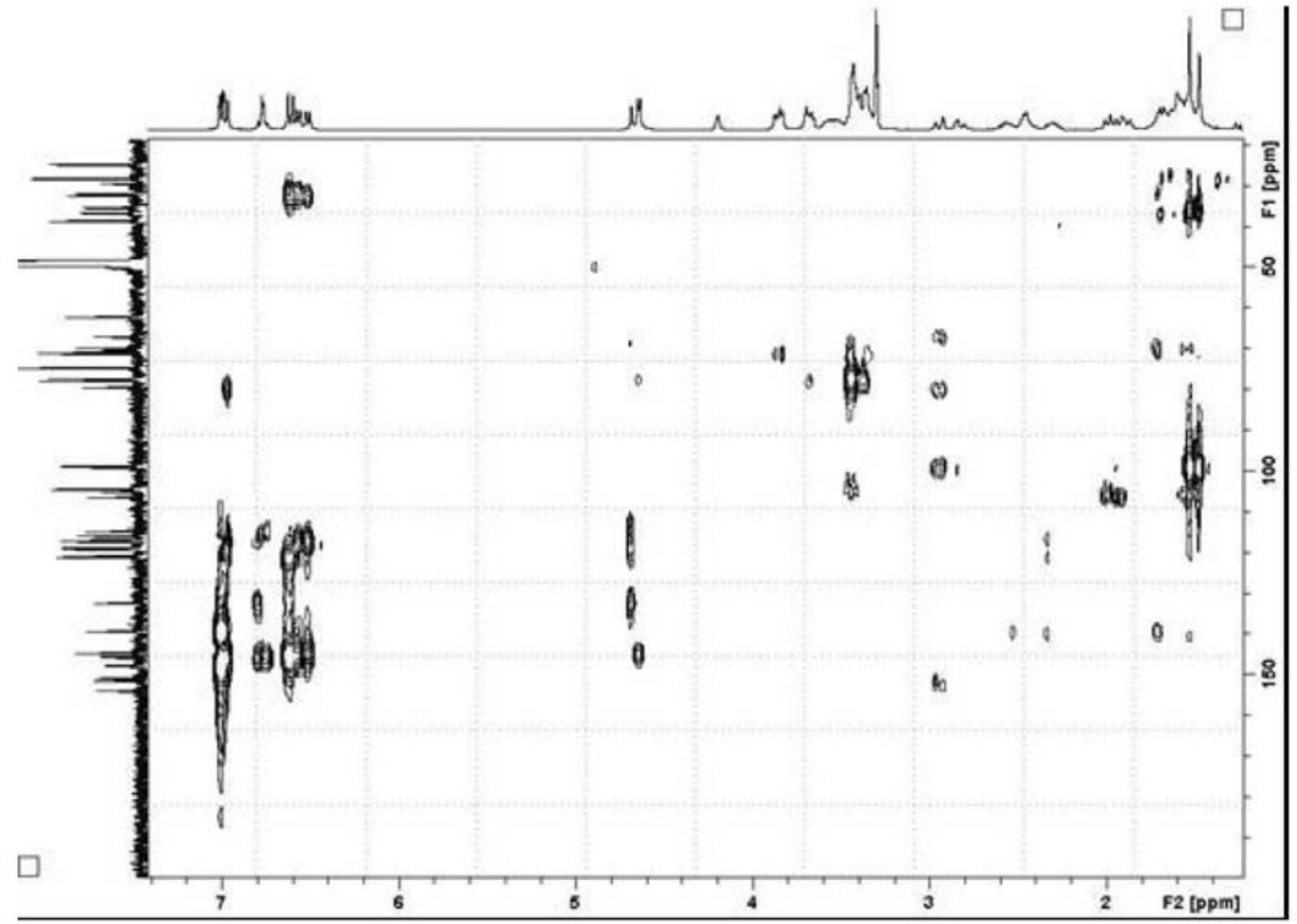

Figure S12. HMBC spectrum $\left(\mathrm{CD}_{3} \mathrm{OD}\right)$ of compound $\mathbf{1}$. 


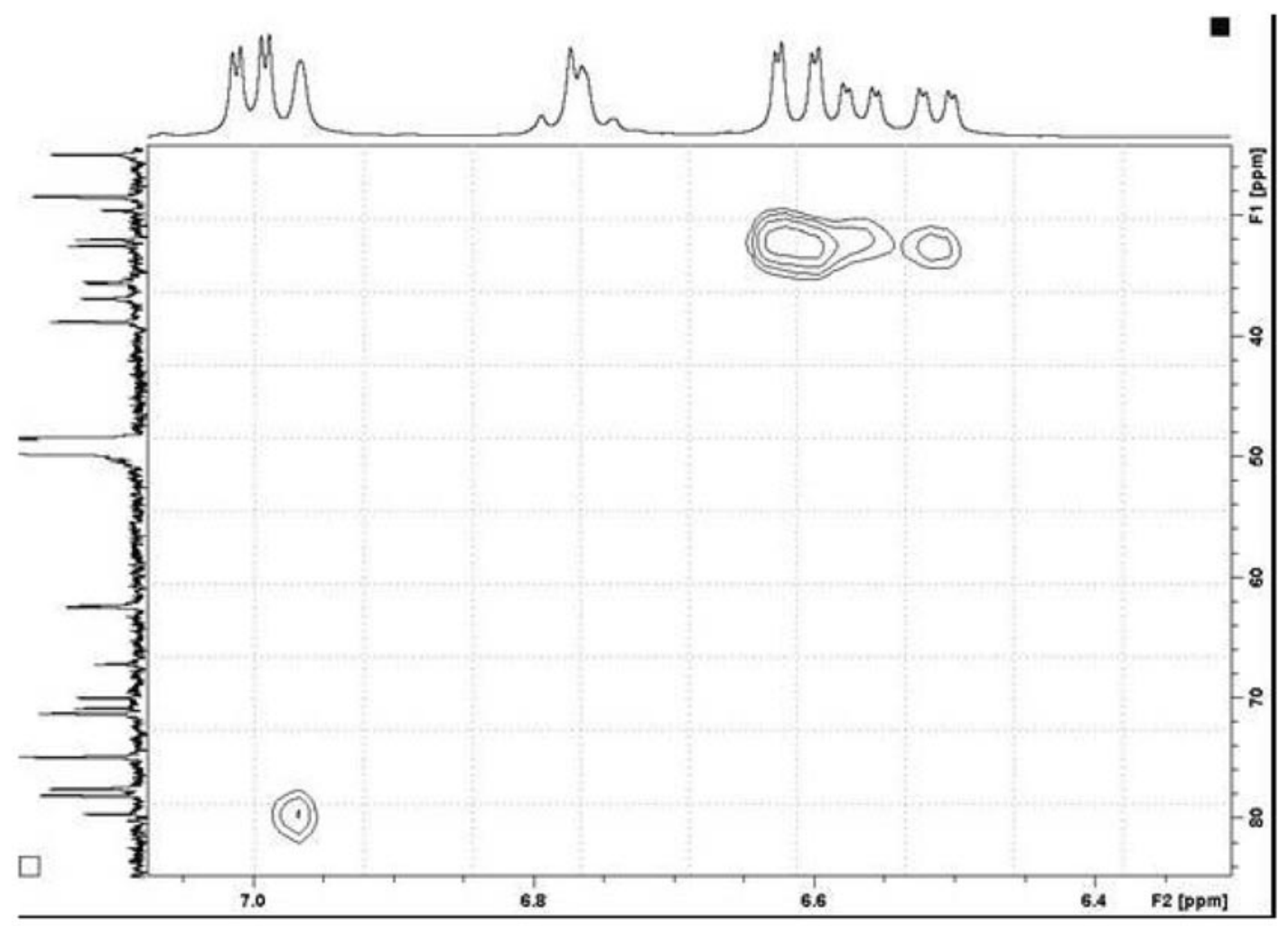

Figure S13. HMBC spectrum of compound 1 (expansion).

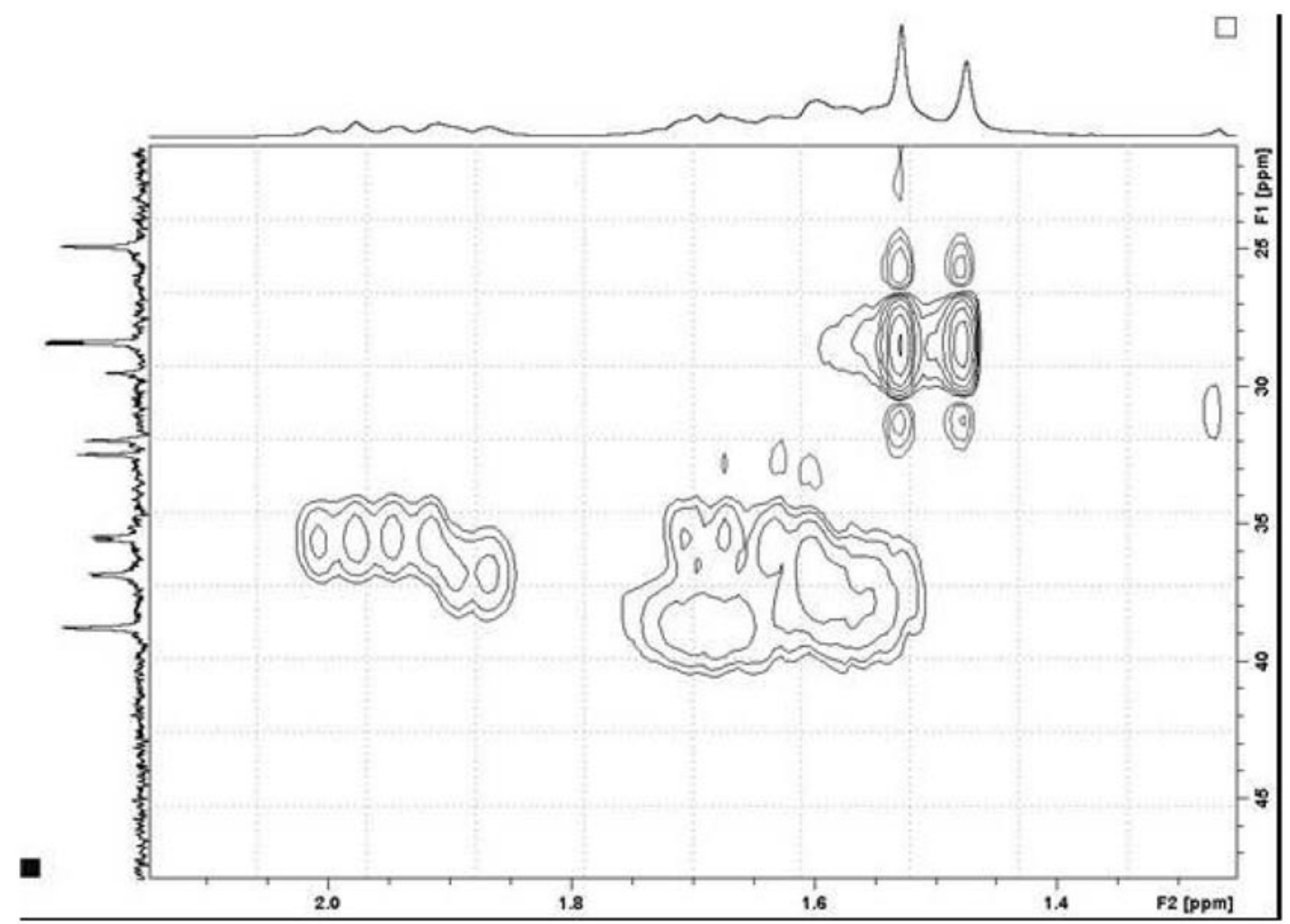

Figure S14. HMBC spectrum of compound 1 (expansion). 
S10

Two Unusual Epicatechin and Epiafzelechin Derivatives from Mascagnia pubiflora

J. Braz. Chem. Soc.

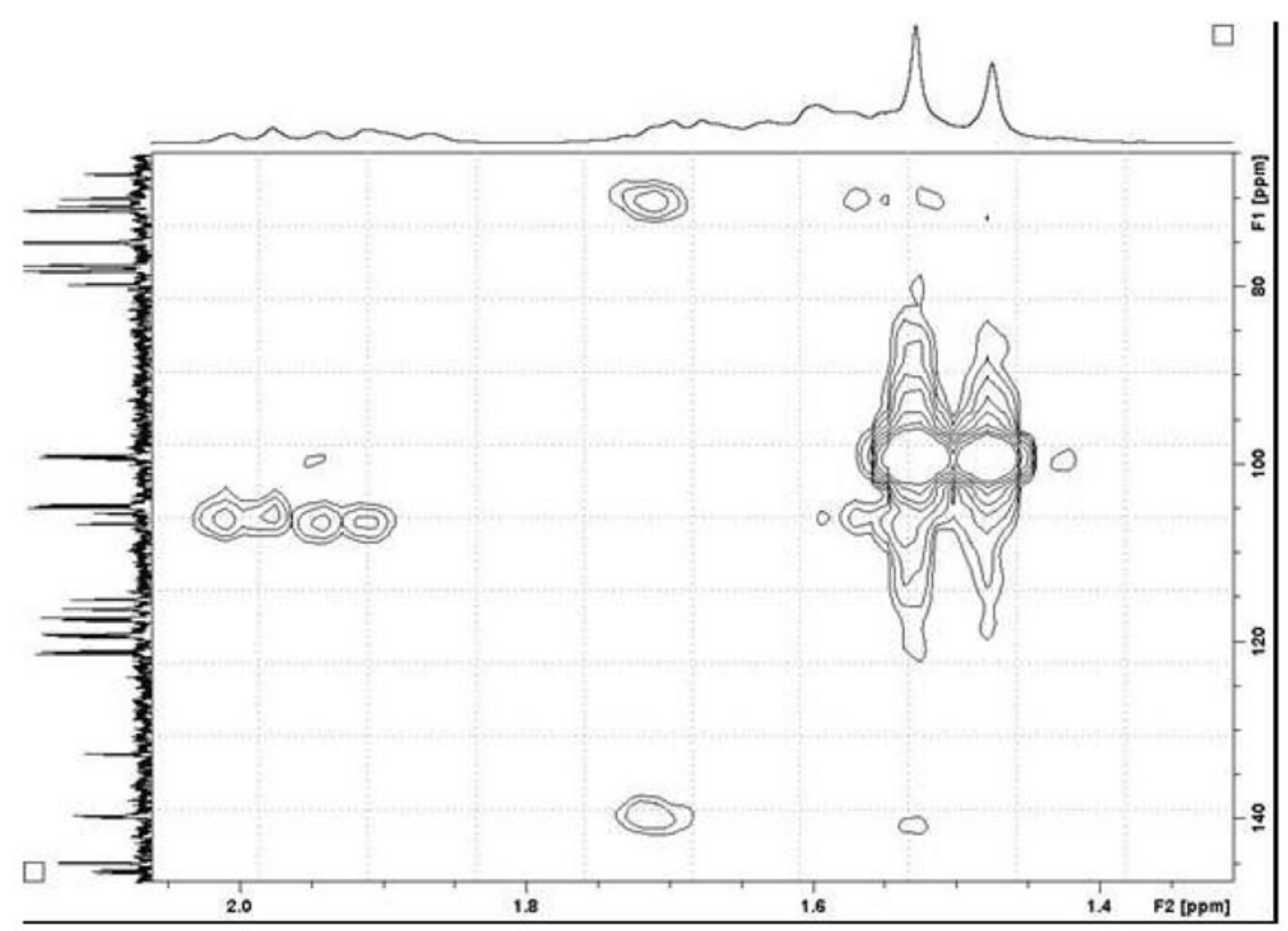

Figure S15. HMBC spectrum of compound 1 (expansion).

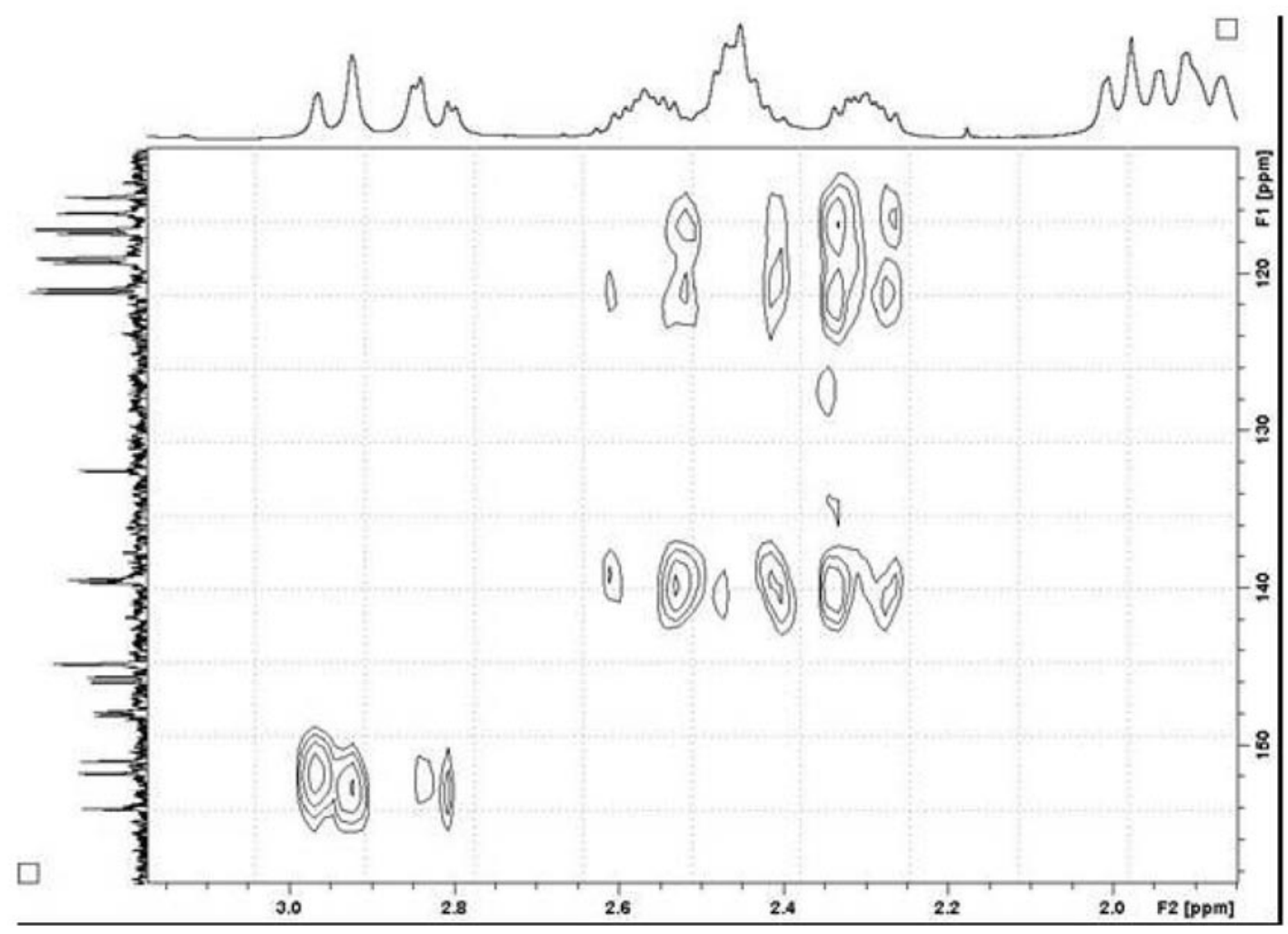

Figure S16. HMBC spectrum of compound 1 (expansion). 


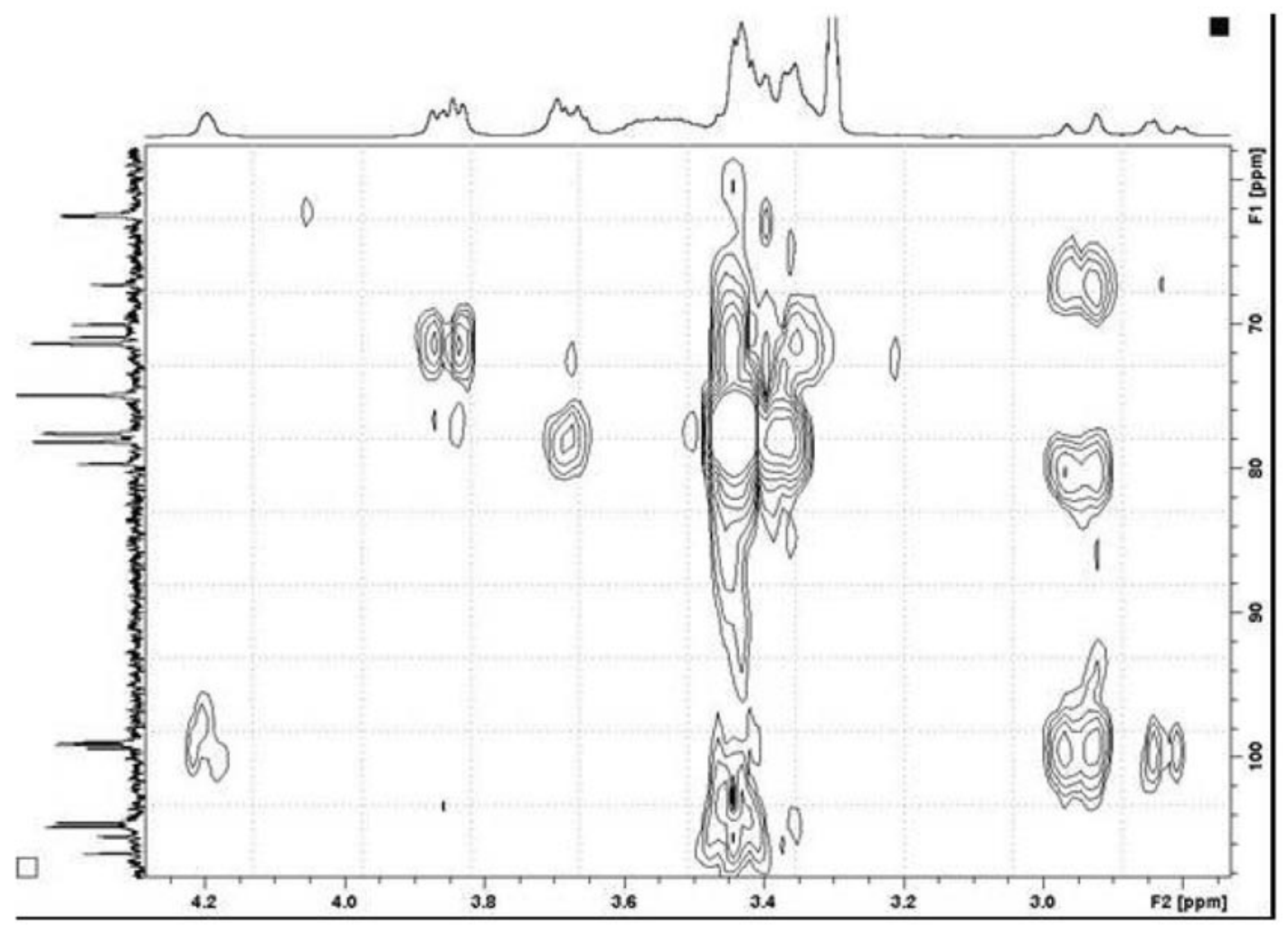

Figure S17. HMBC spectrum of compound 1 (expansion).

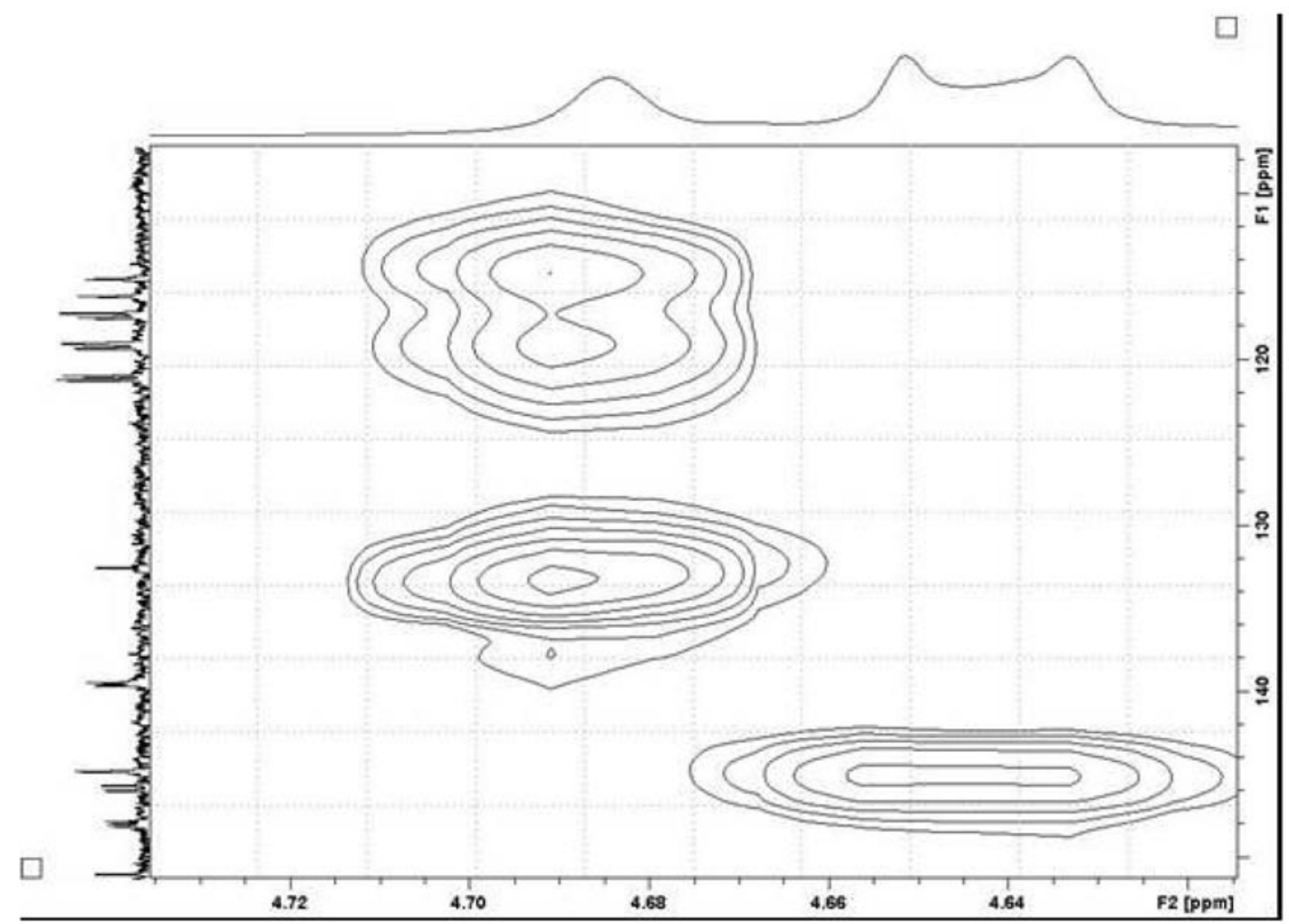

Figure S18. HMBC spectrum of compound 1 (expansion). 


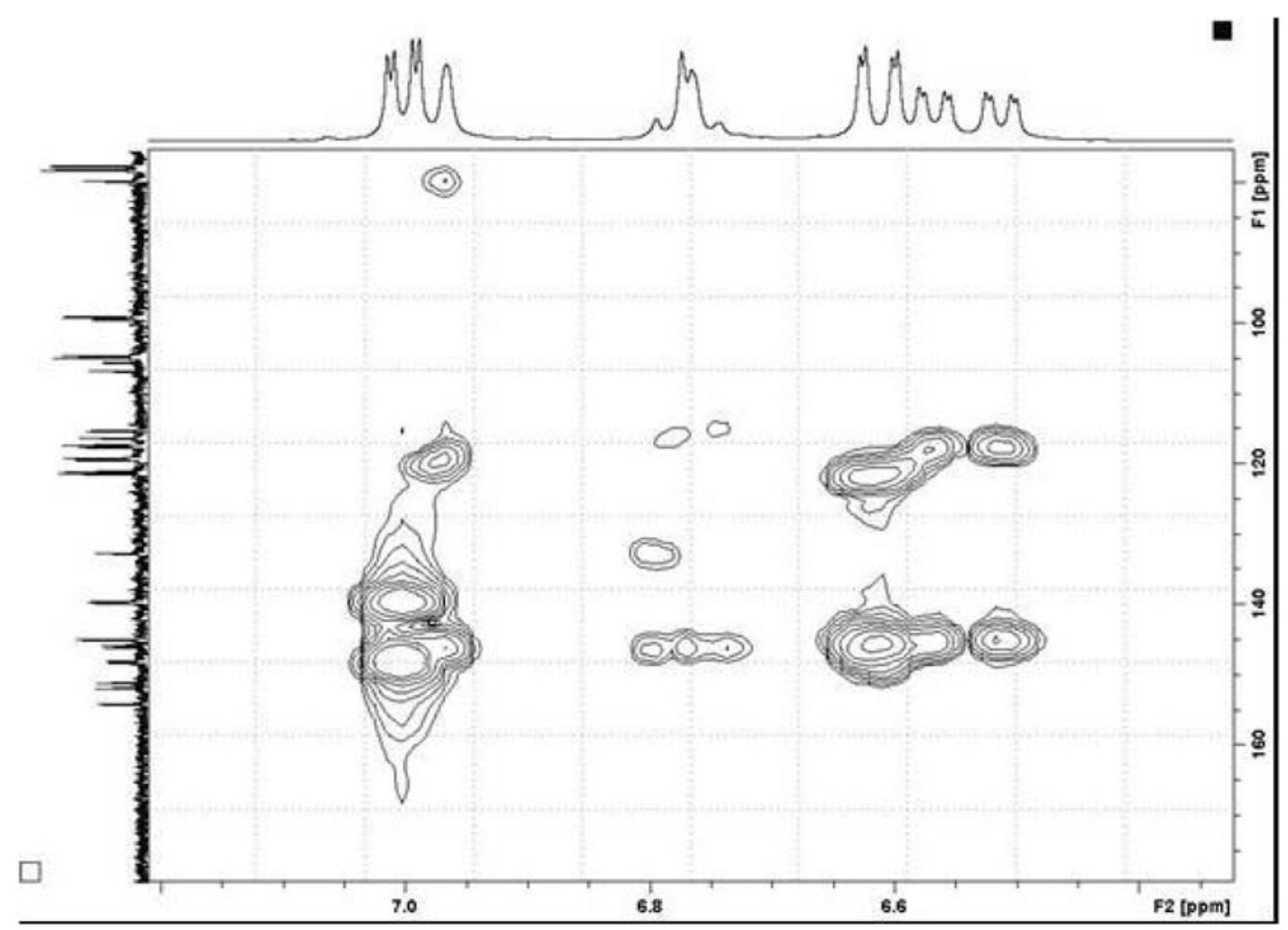

Figure S19. HMBC spectrum of compound 1 (expansion).

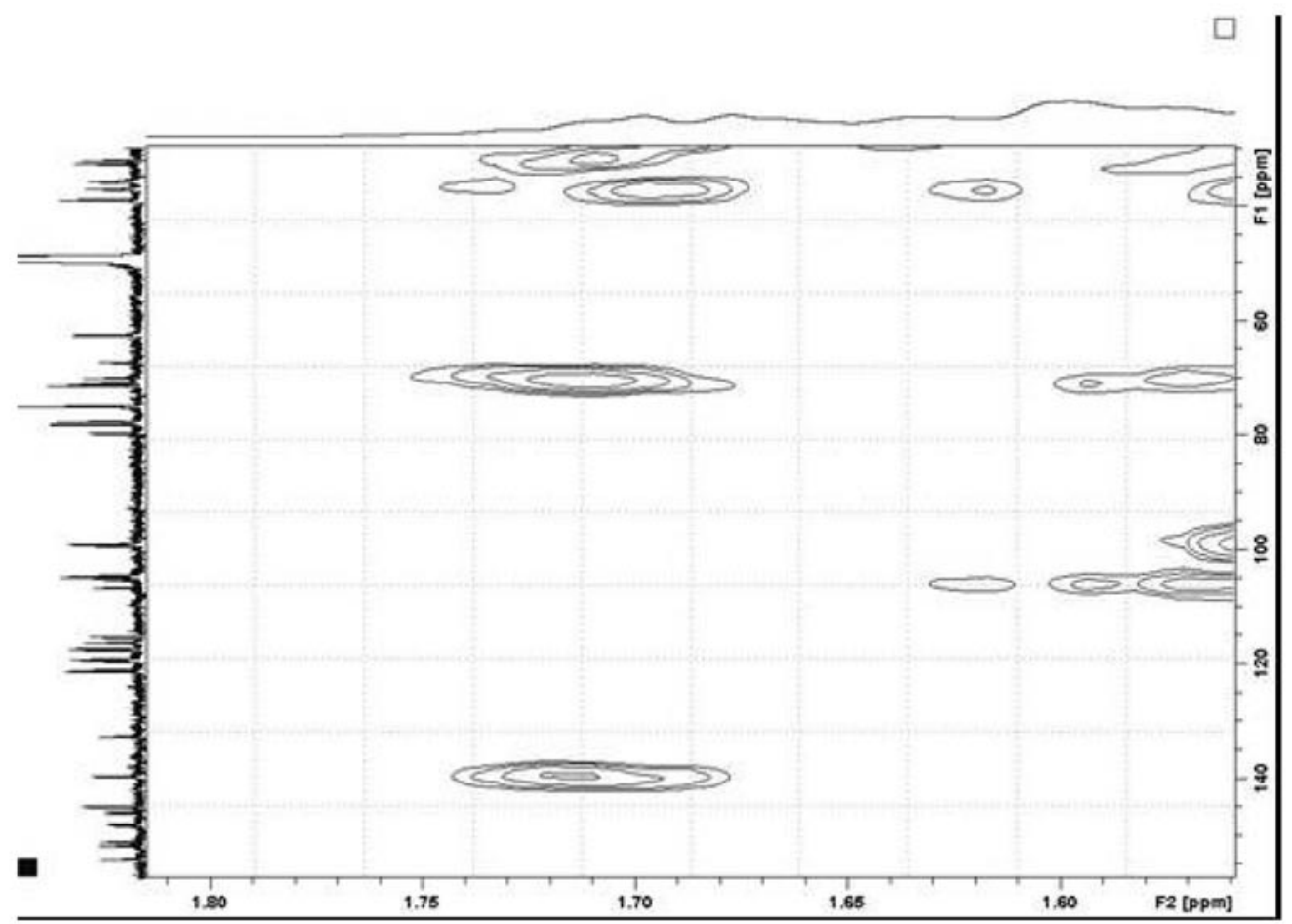

Figure S20. HMBC spectrum of compound 1 (expansion). 


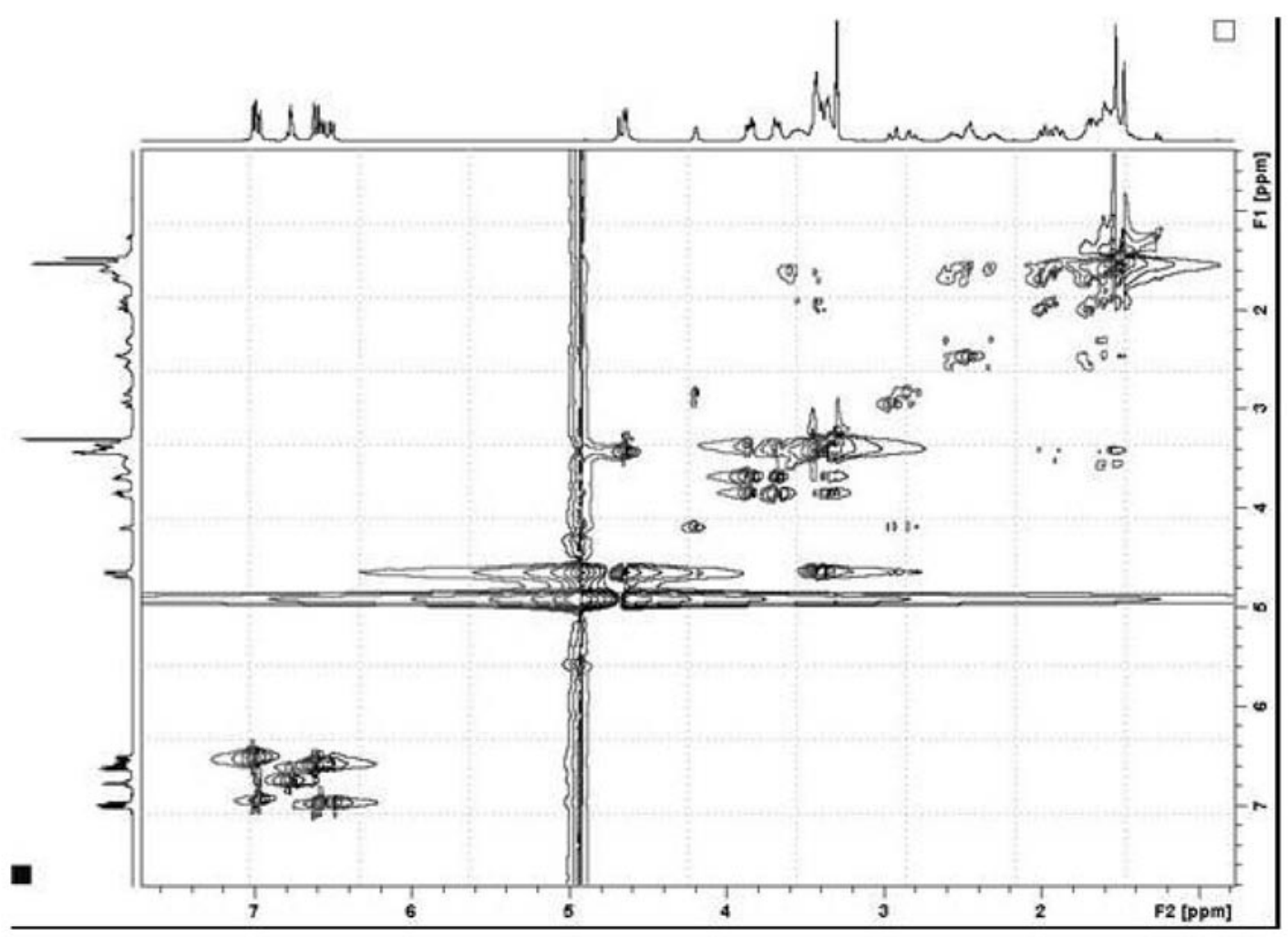

Figure S21. NOESY spectrum $\left(\mathrm{CD}_{3} \mathrm{OD}\right)$ of compound $\mathbf{1}$.

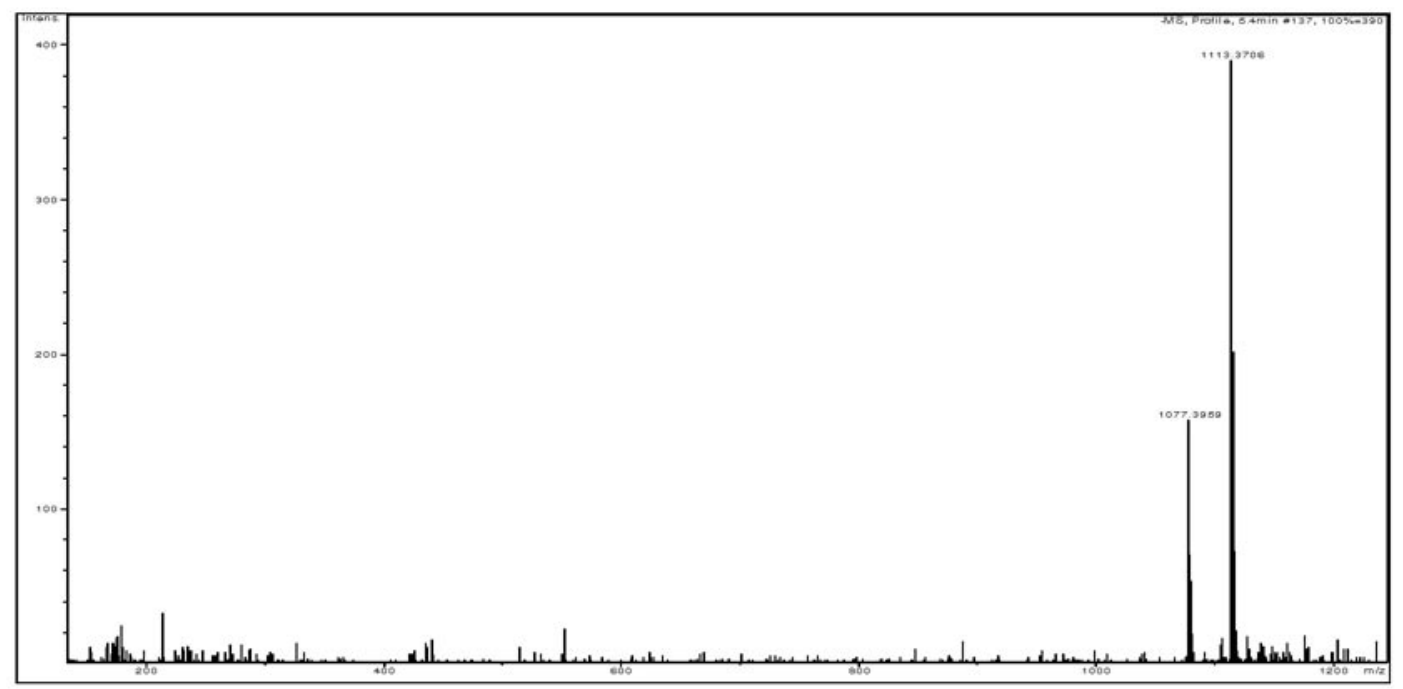

Figure S22. HRESIMS of compound 1. 


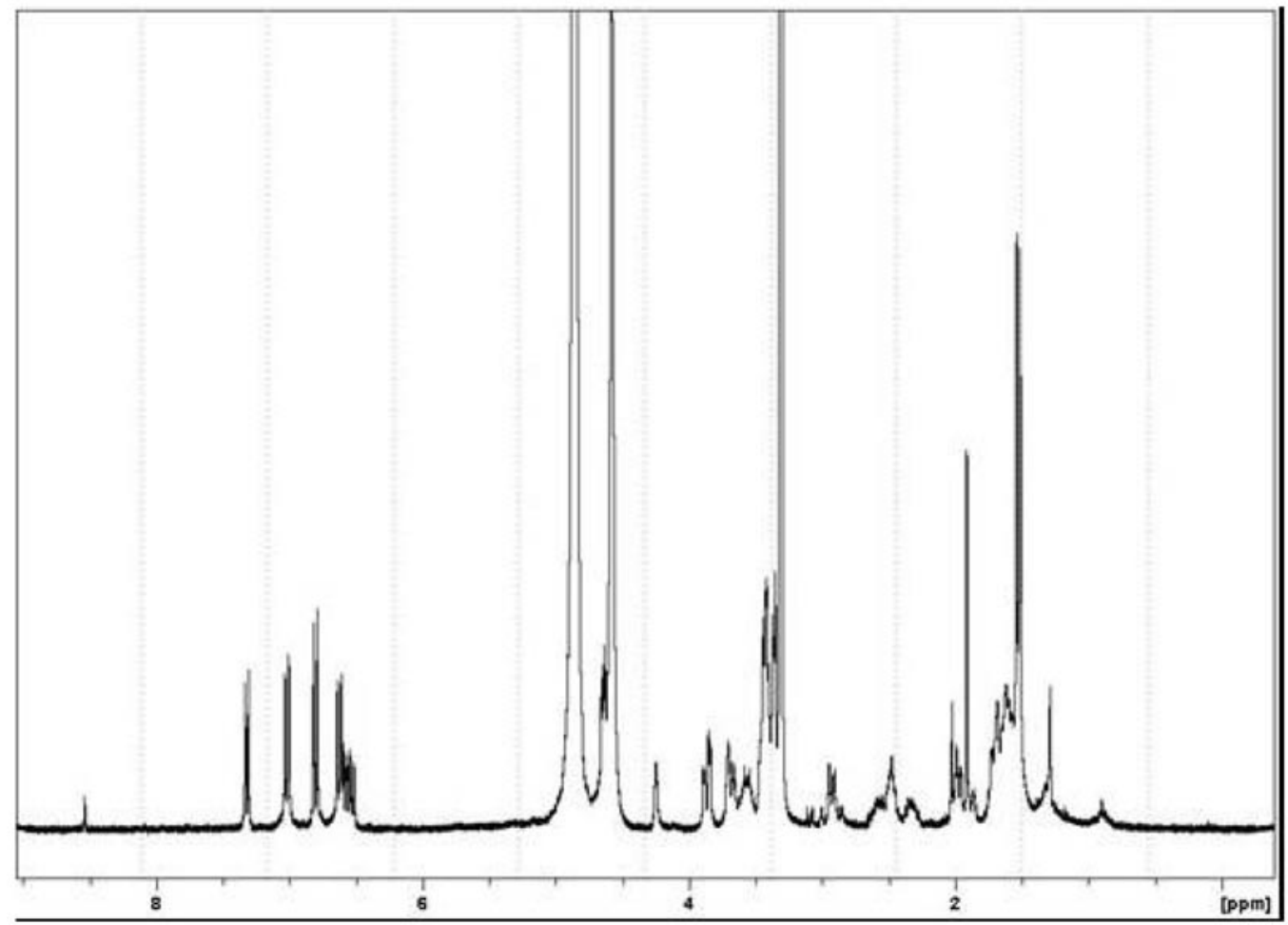

Figure S23. ${ }^{1} \mathrm{H}$ NMR spectrum $\left(300 \mathrm{MHz}, \mathrm{CD}_{3} \mathrm{OD}\right)$ of compound 2. 

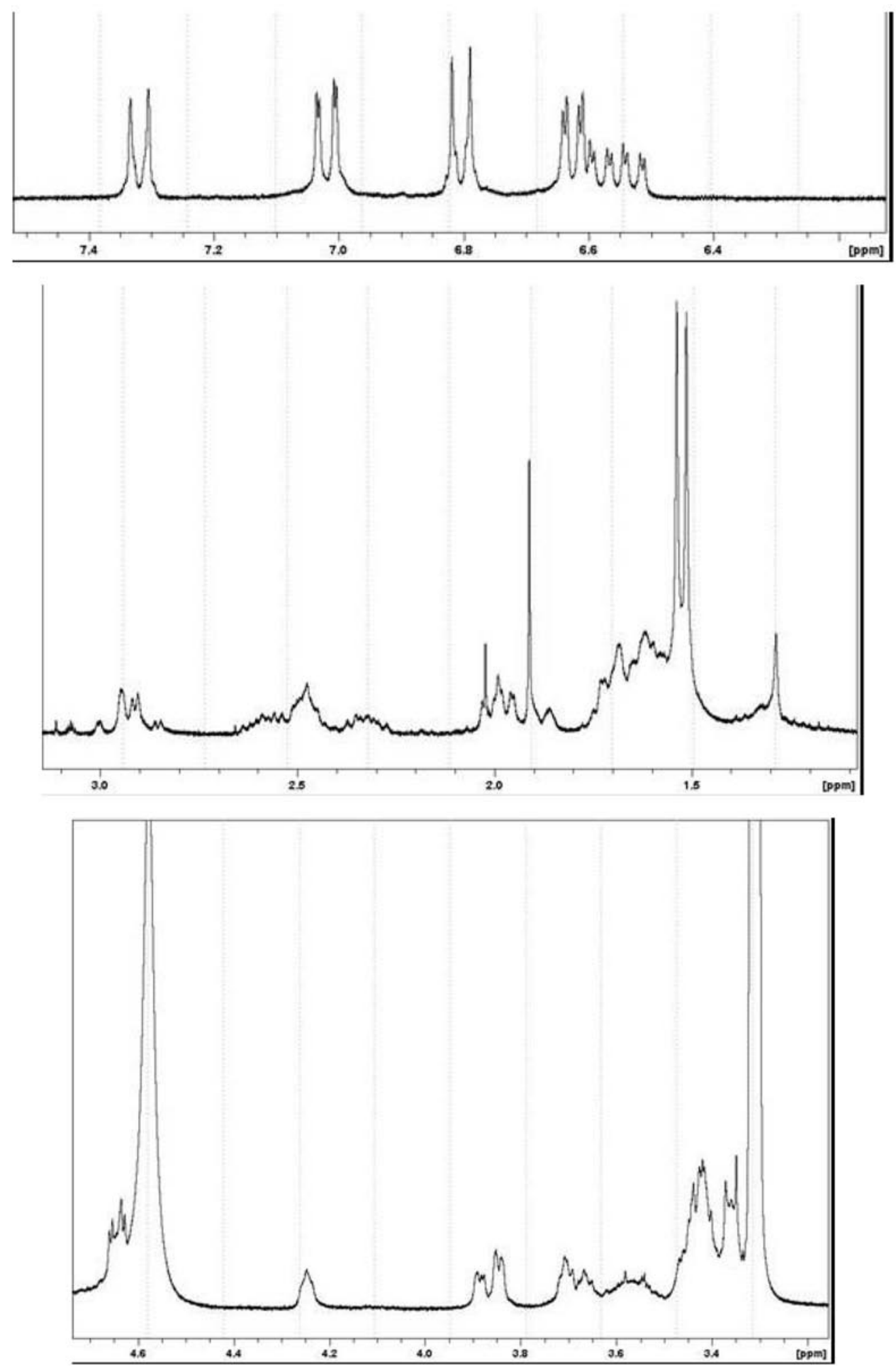

Figure S24. ${ }^{1} \mathrm{H}$ NMR spectrum ( $300 \mathrm{MHz}, \mathrm{CD}_{3} \mathrm{OD}$ ) of compound 2 (expansions). 


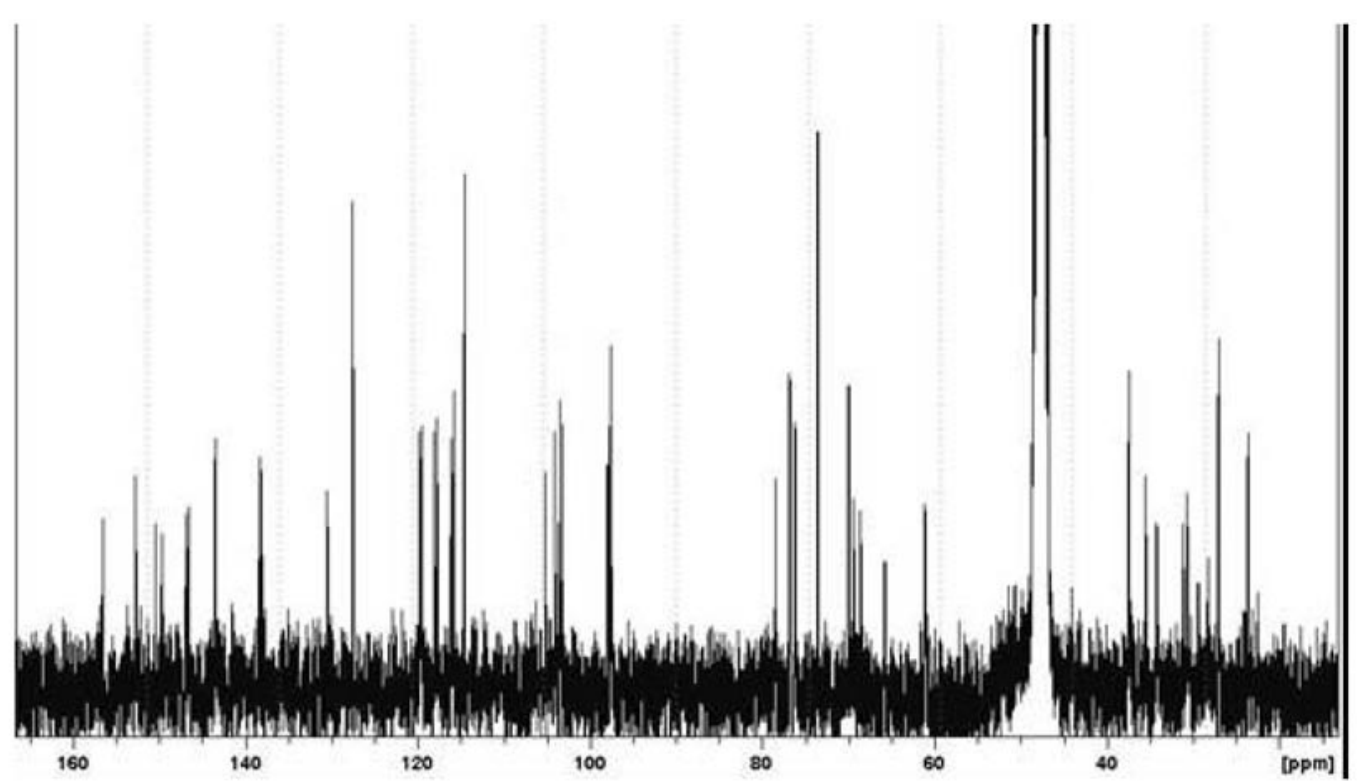

Figure S25. ${ }^{13} \mathrm{C}$ NMR spectrum $\left(75 \mathrm{MHz}, \mathrm{CD}_{3} \mathrm{OD}\right)$ of compound 2.

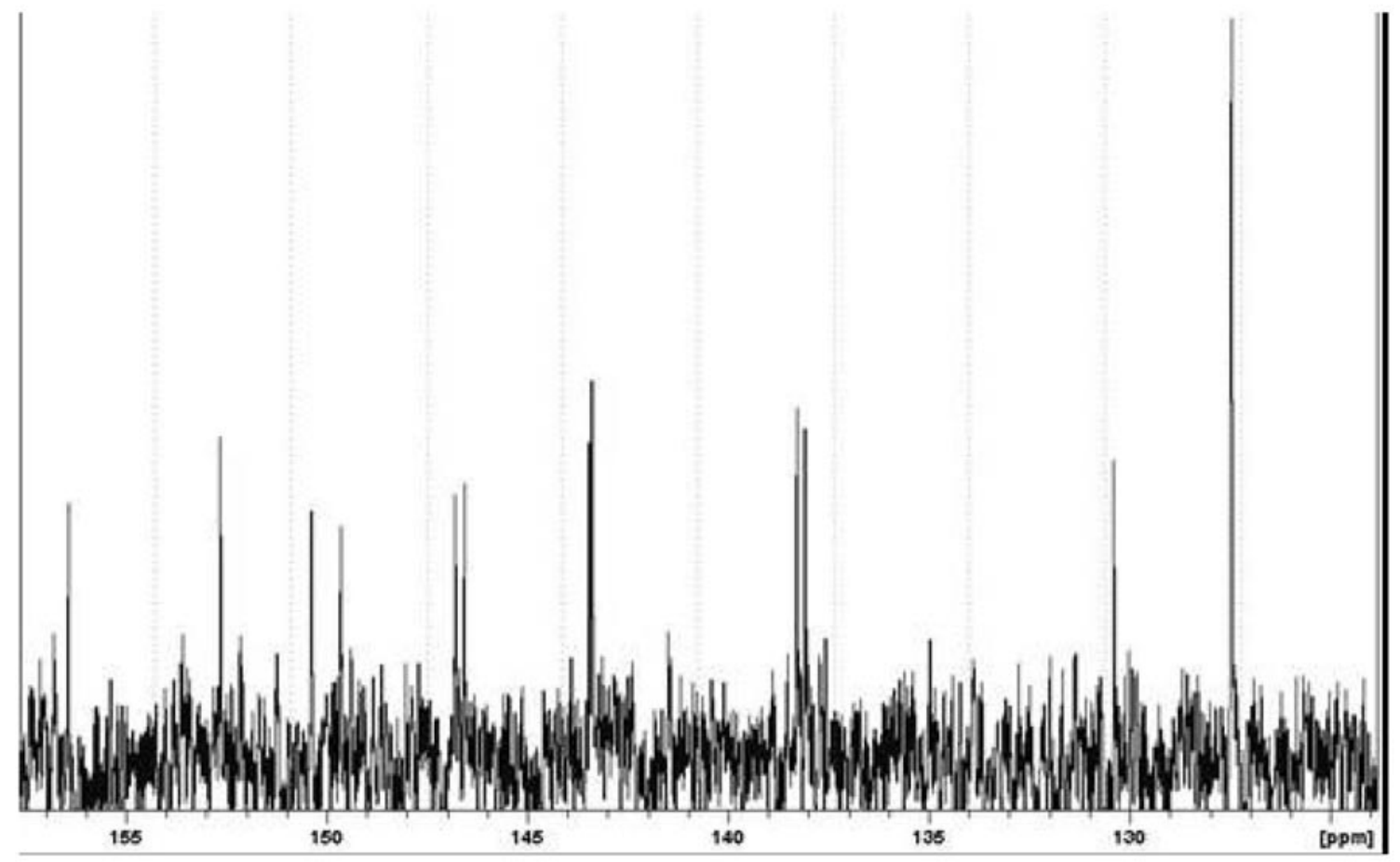

Figure S26. ${ }^{13} \mathrm{C}$ NMR spectrum ( $75 \mathrm{MHz}, \mathrm{CD}_{3} \mathrm{OD}$ ) of compound 2 (expansion). 

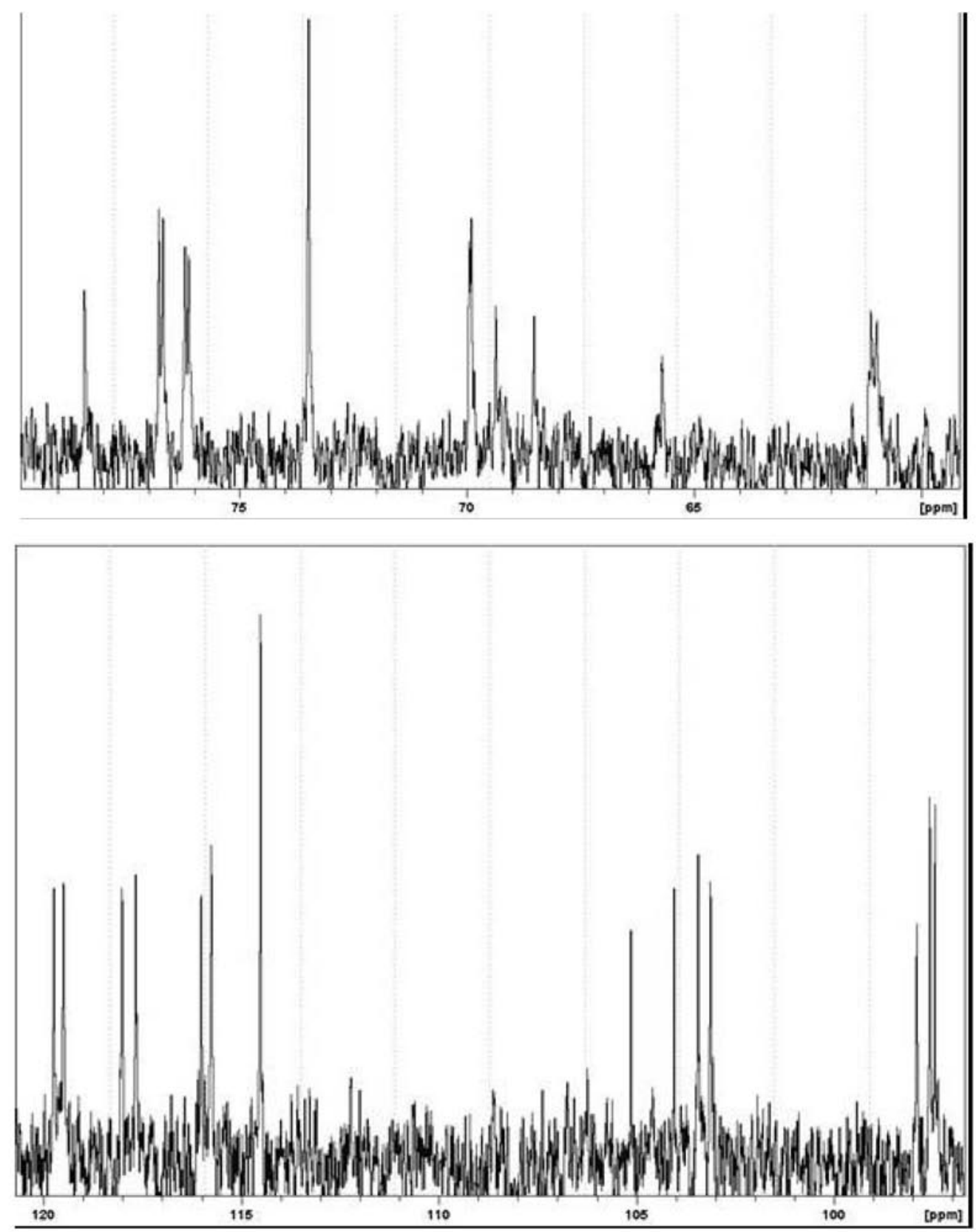

Figure S27. ${ }^{13} \mathrm{C}$ NMR spectrum (75 MHz, $\mathrm{CD}_{3} \mathrm{OD}$ ) of compound 2 (expansions). 
S18

Two Unusual Epicatechin and Epiafzelechin Derivatives from Mascagnia pubiflora

J. Braz. Chem. Soc.

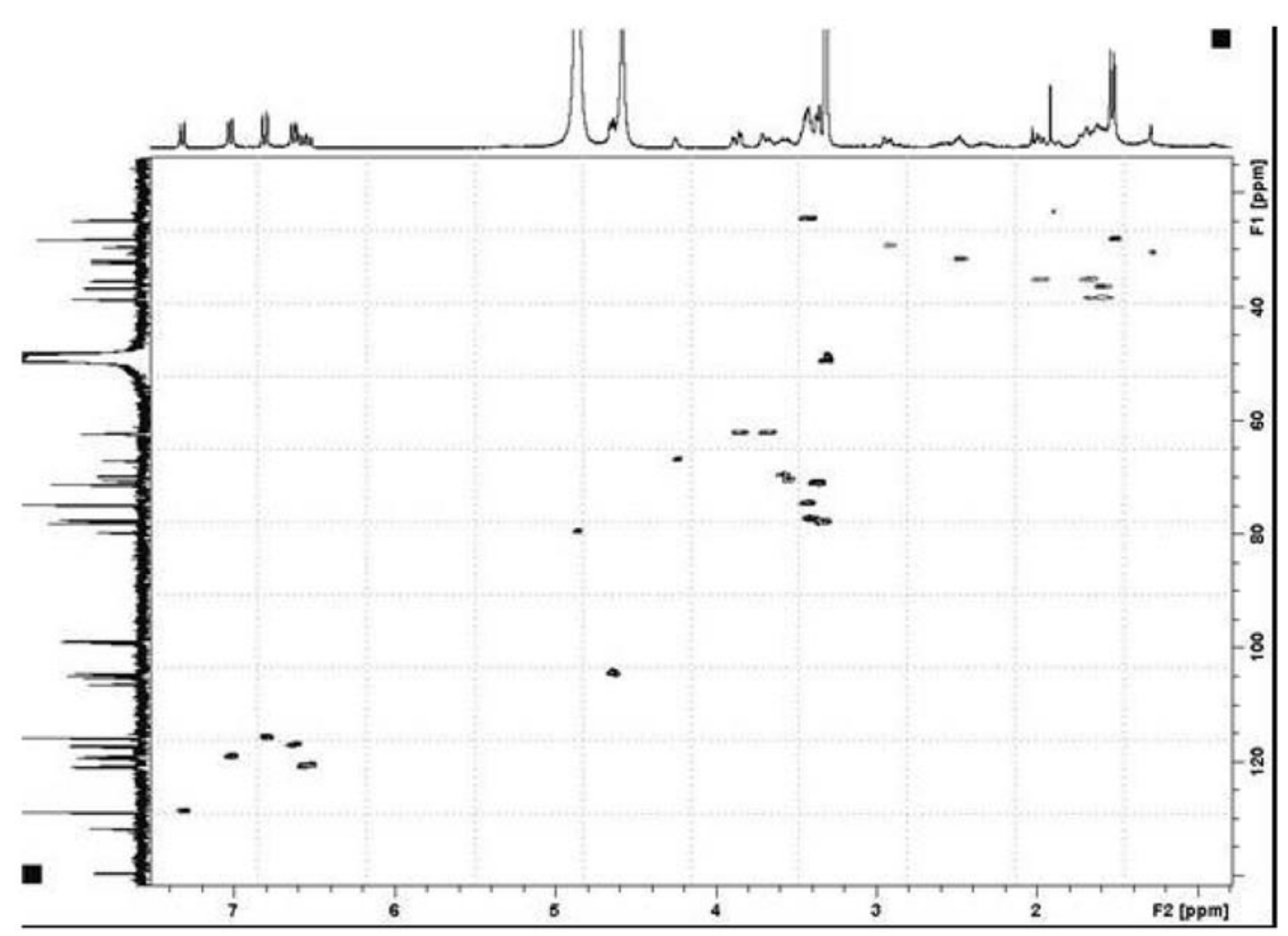

Figure S28. HSQC spectrum $\left(\mathrm{CD}_{3} \mathrm{OD}\right)$ of compound 2.

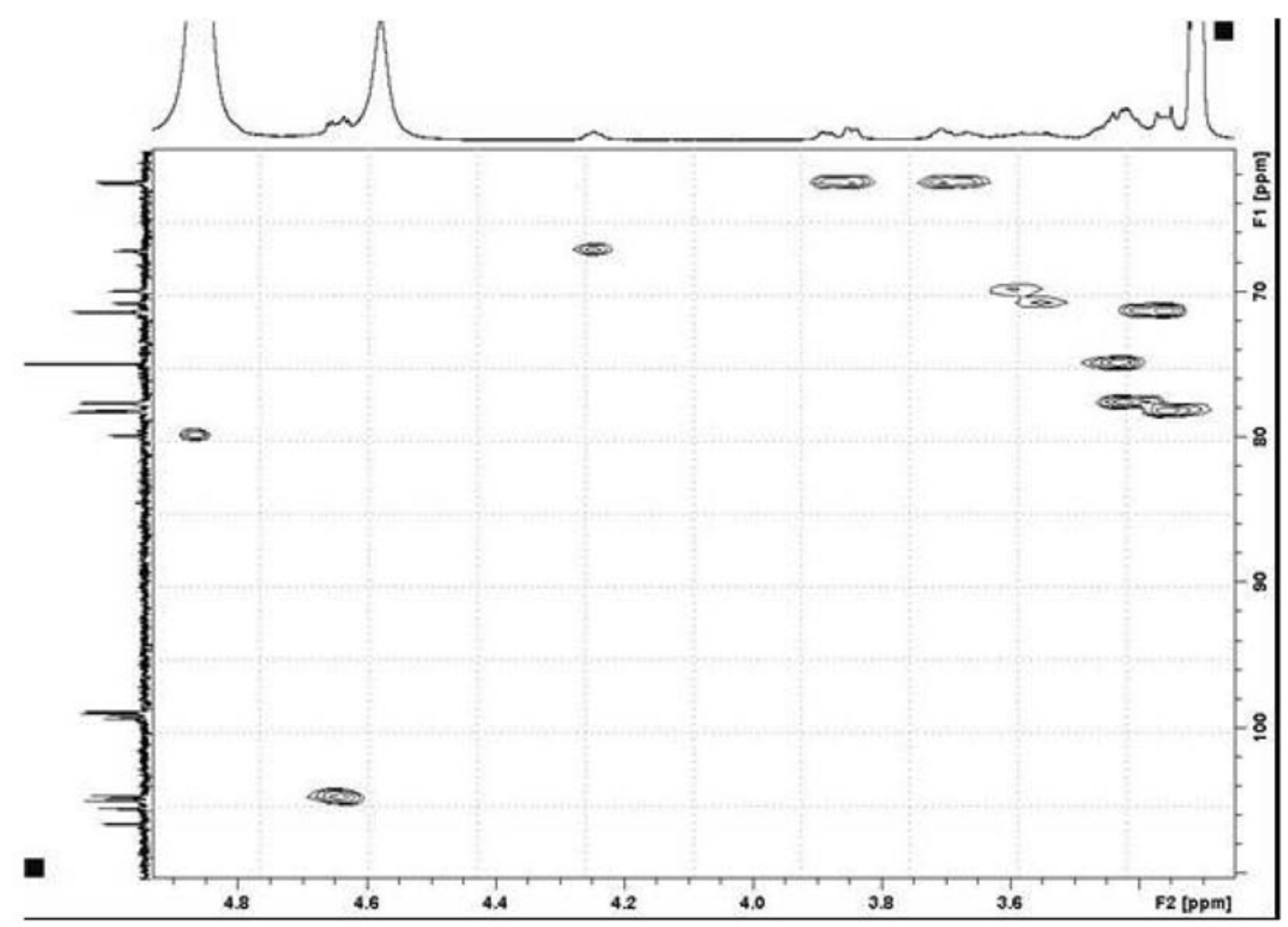

Figure S29. HSQC spectrum of compound 2 (expansion). 
Vol. 20, No. 4, 2009

Garcez et al.

S19

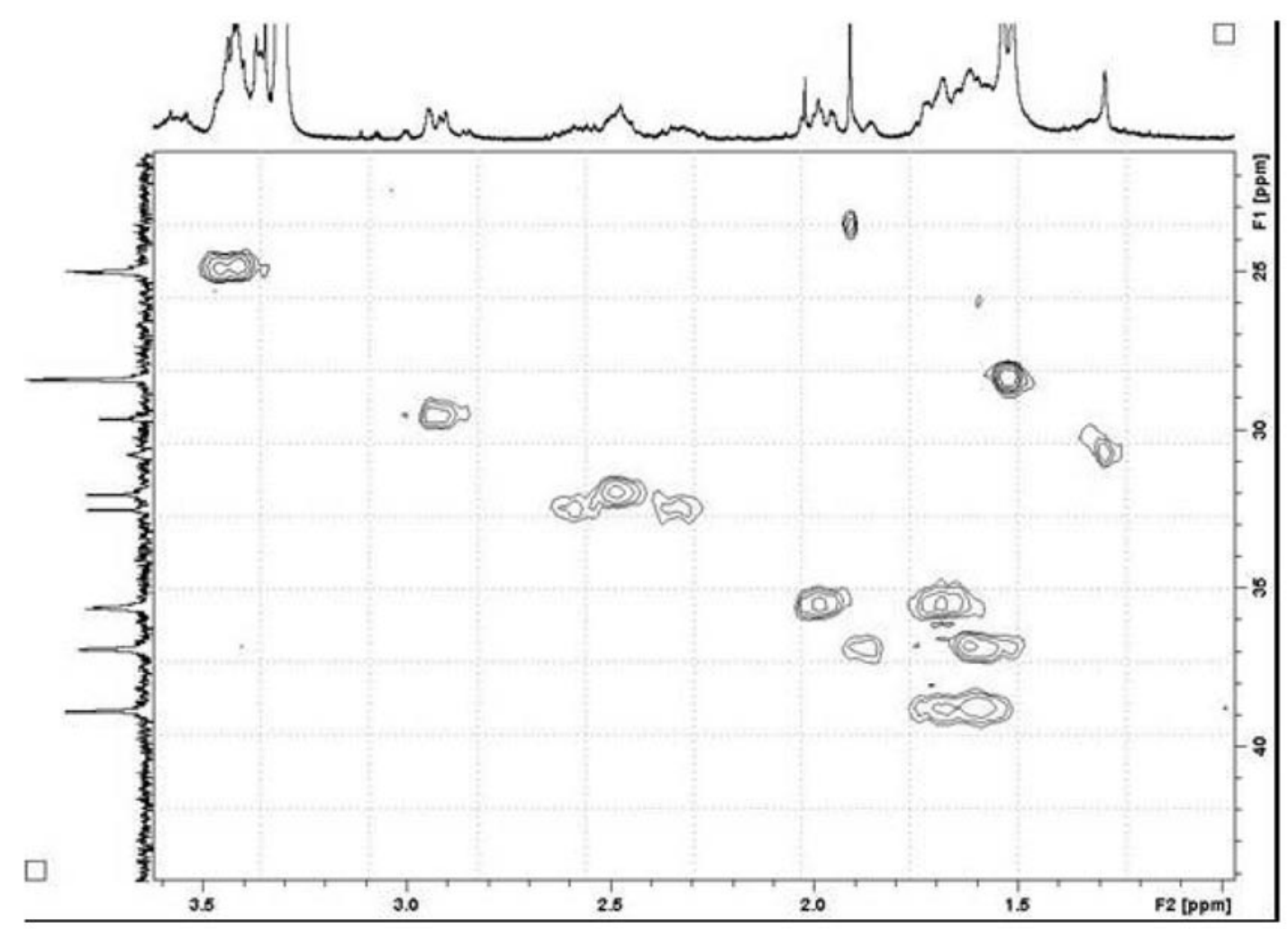

Figure S30. HSQC spectrum of compound 2 (expansion).

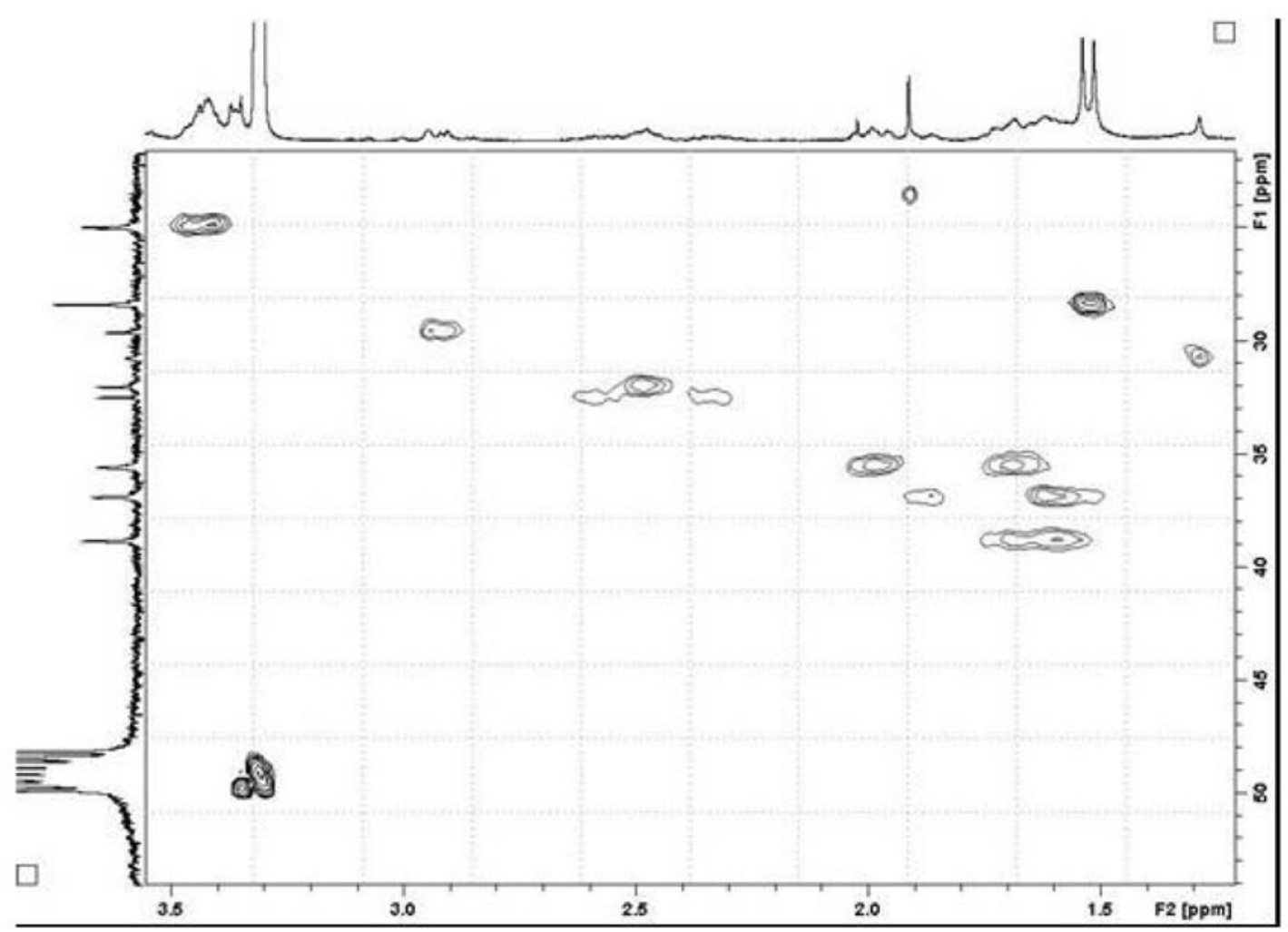

Figure S31. HSQC spectrum of compound 2 (expansion). 
S20

Two Unusual Epicatechin and Epiafzelechin Derivatives from Mascagni pubiflora

J. Braz. Chem. Soc.

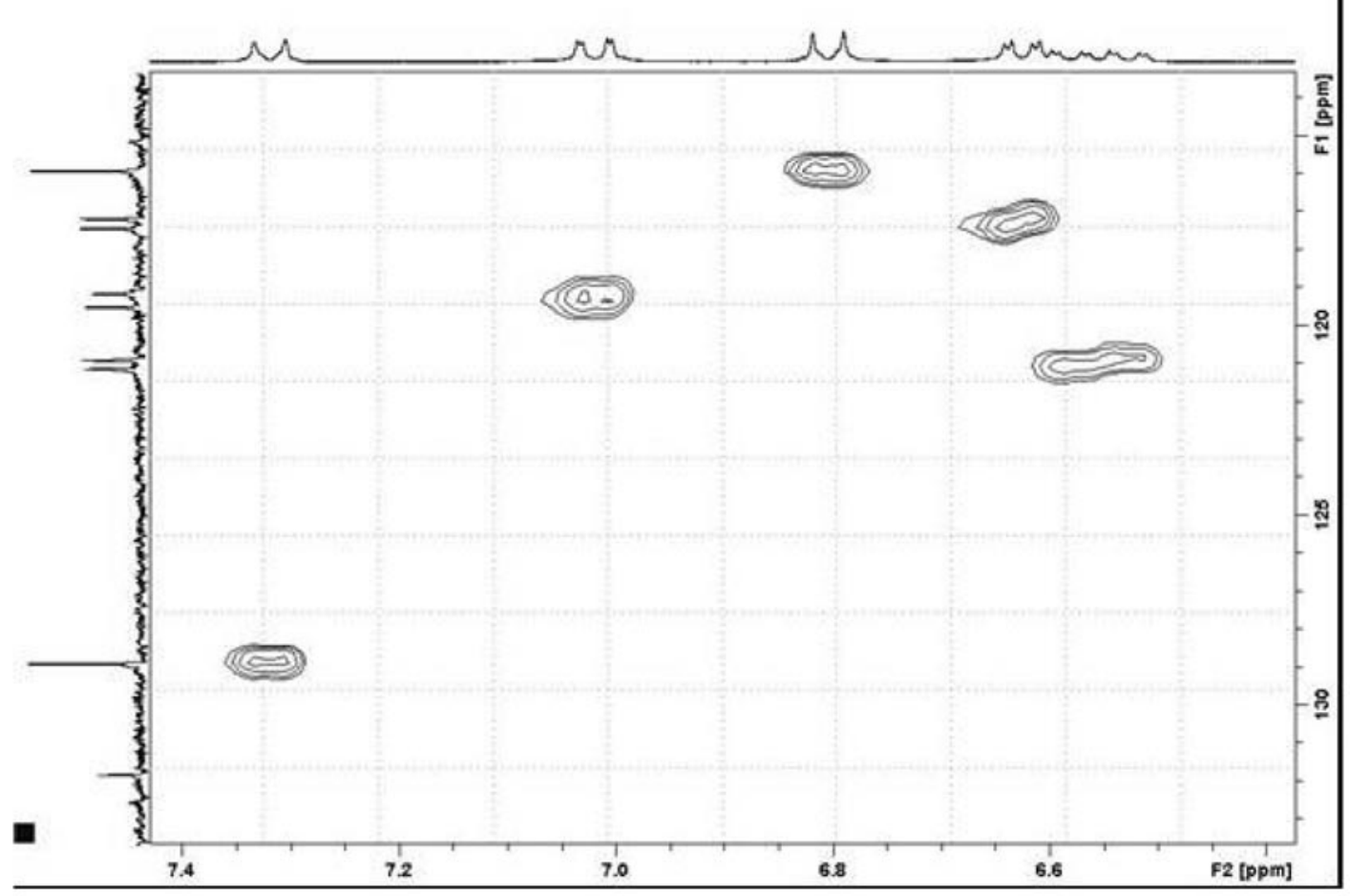

Figure S32. HSQC spectrum of compound 2 (expansion).

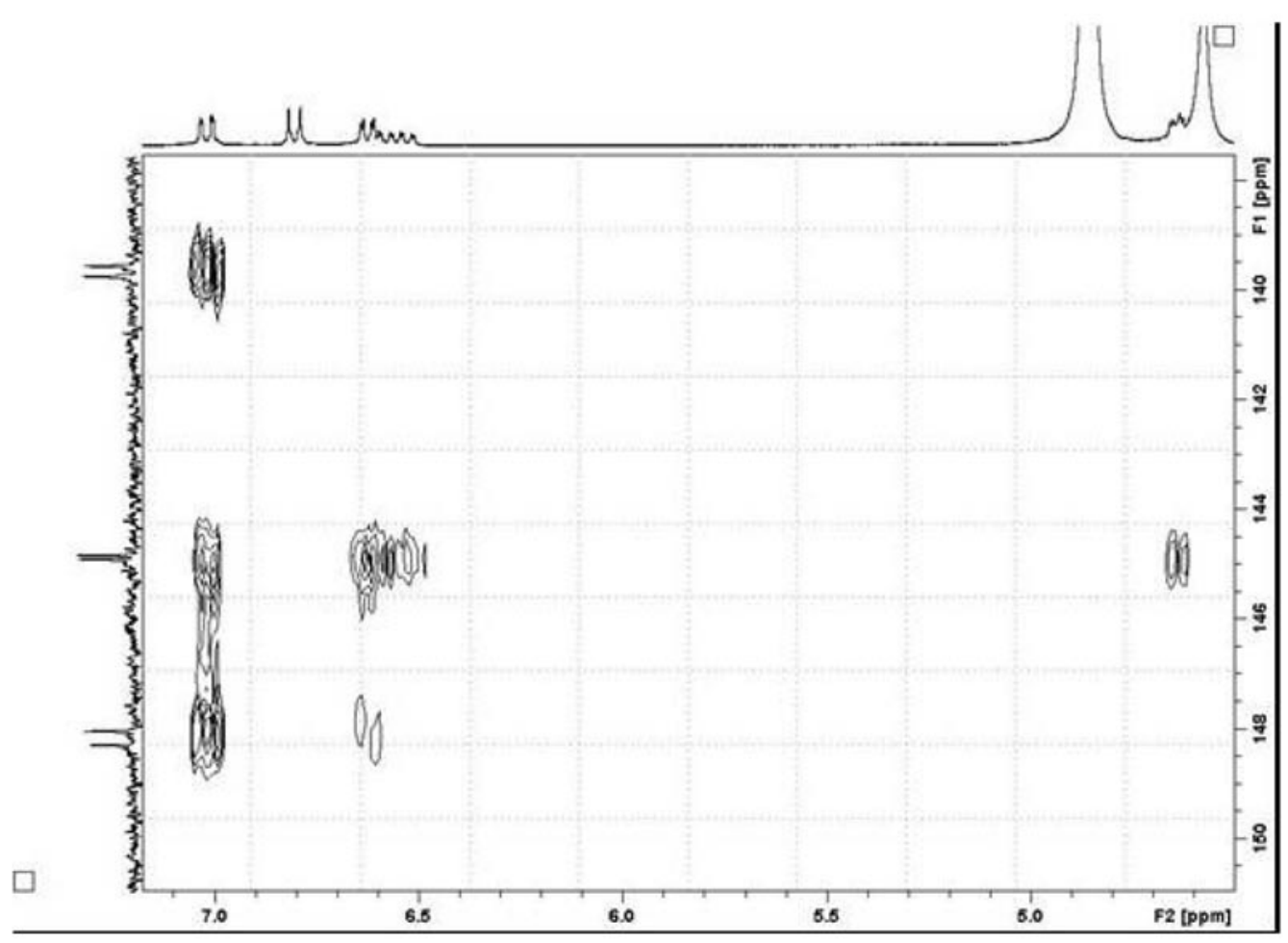

Figure S33. HSQC spectrum of compound 2 (expansion). 


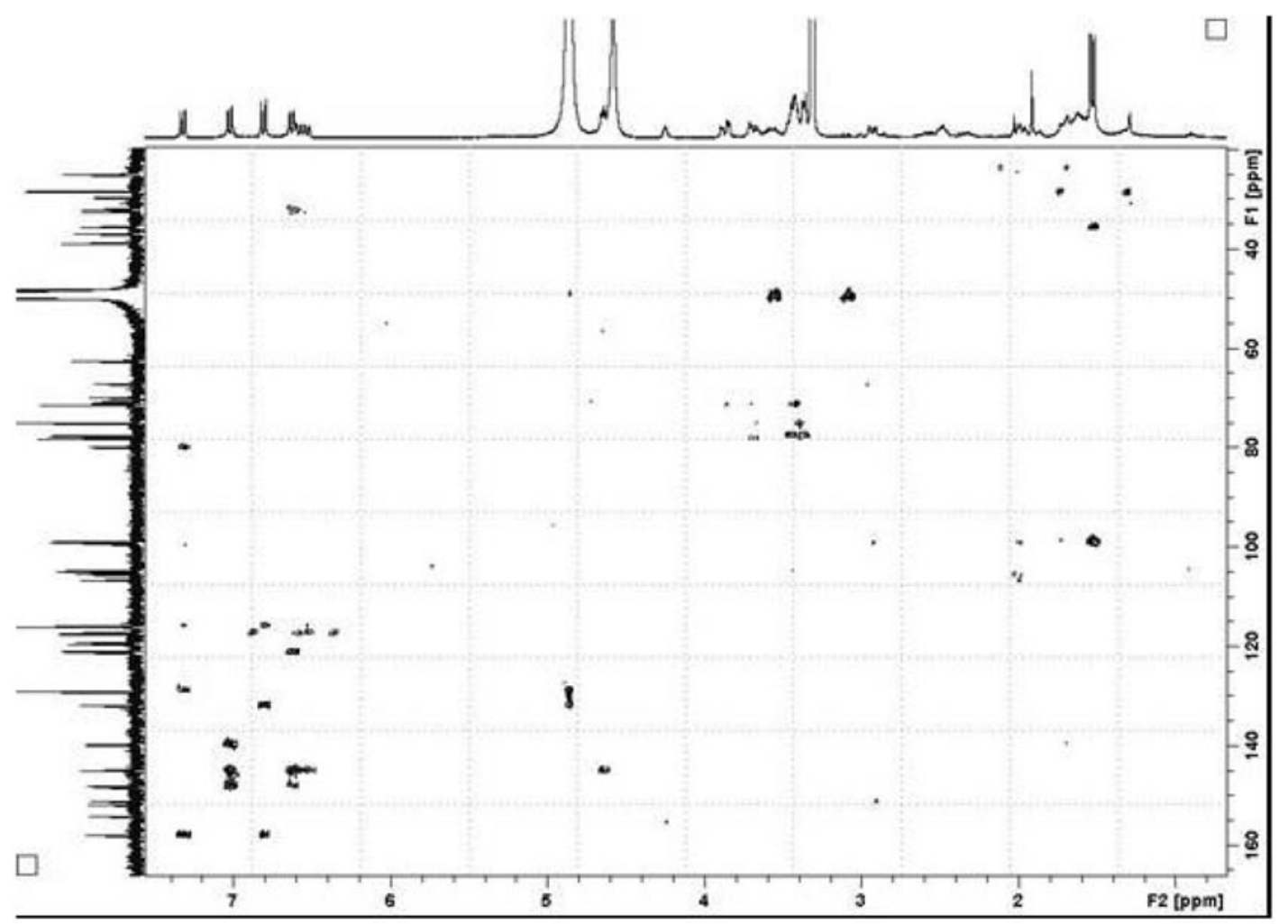

Figure S34. HMBC spectrum $\left(\mathrm{CD}_{3} \mathrm{OD}\right)$ of compound 2.

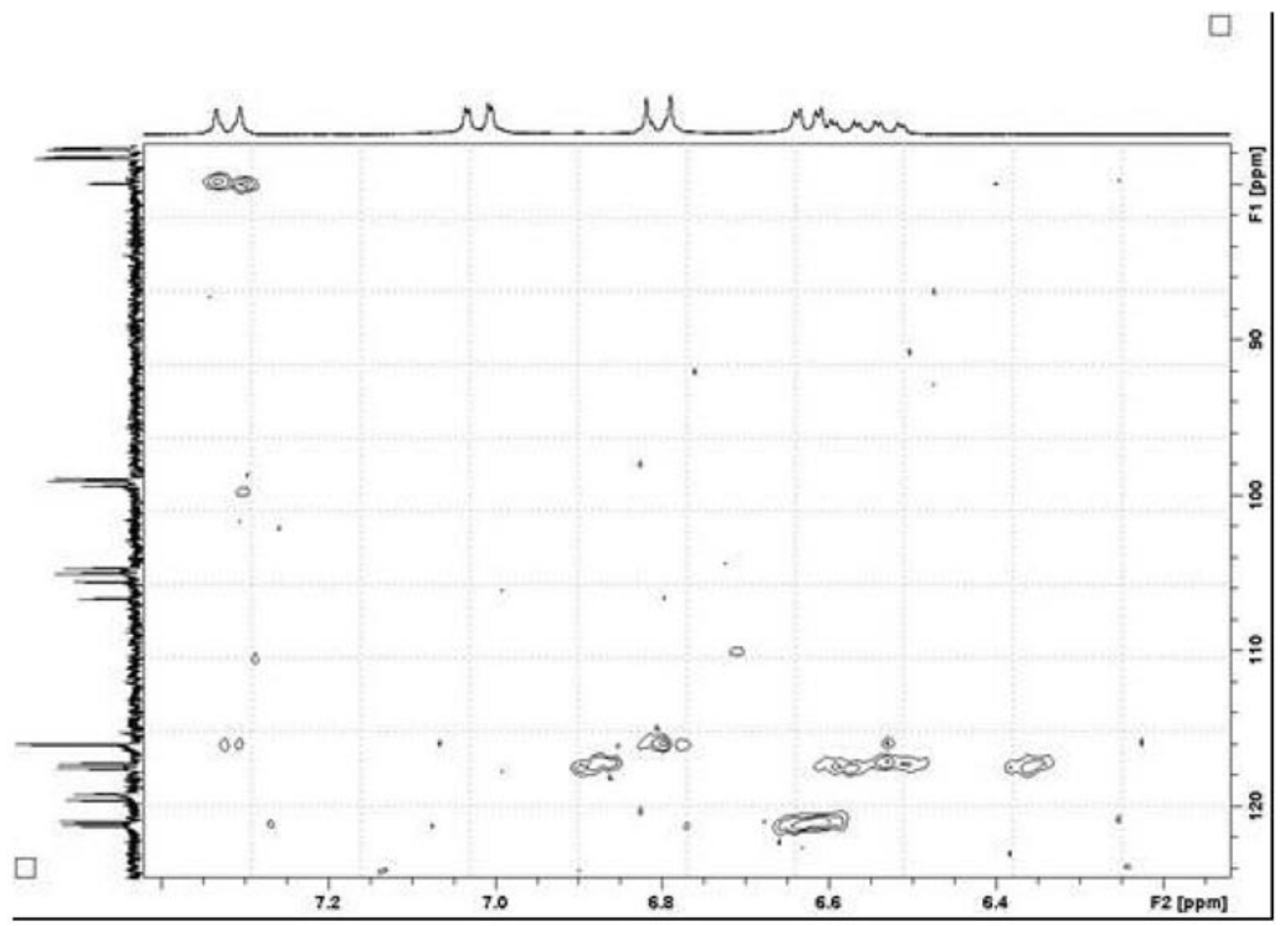

Figure S35. HMBC spectrum of compound 2 (expansion). 
S22

Two Unusual Epicatechin and Epiafzelechin Derivatives from Mascagnia pubiflora

J. Braz. Chem. Soc.

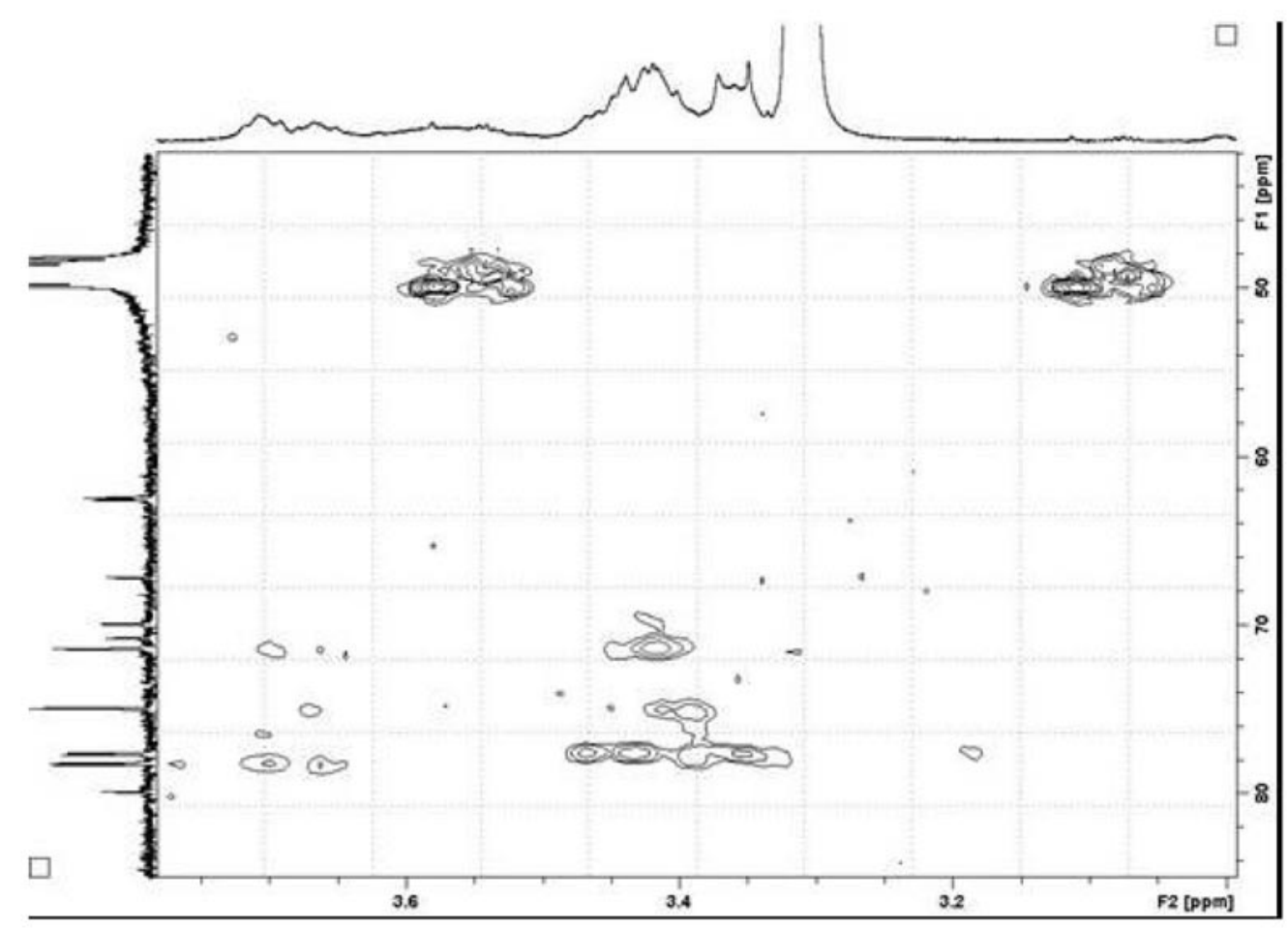

Figure S36. HMBC spectrum of compound 2 (expansion).

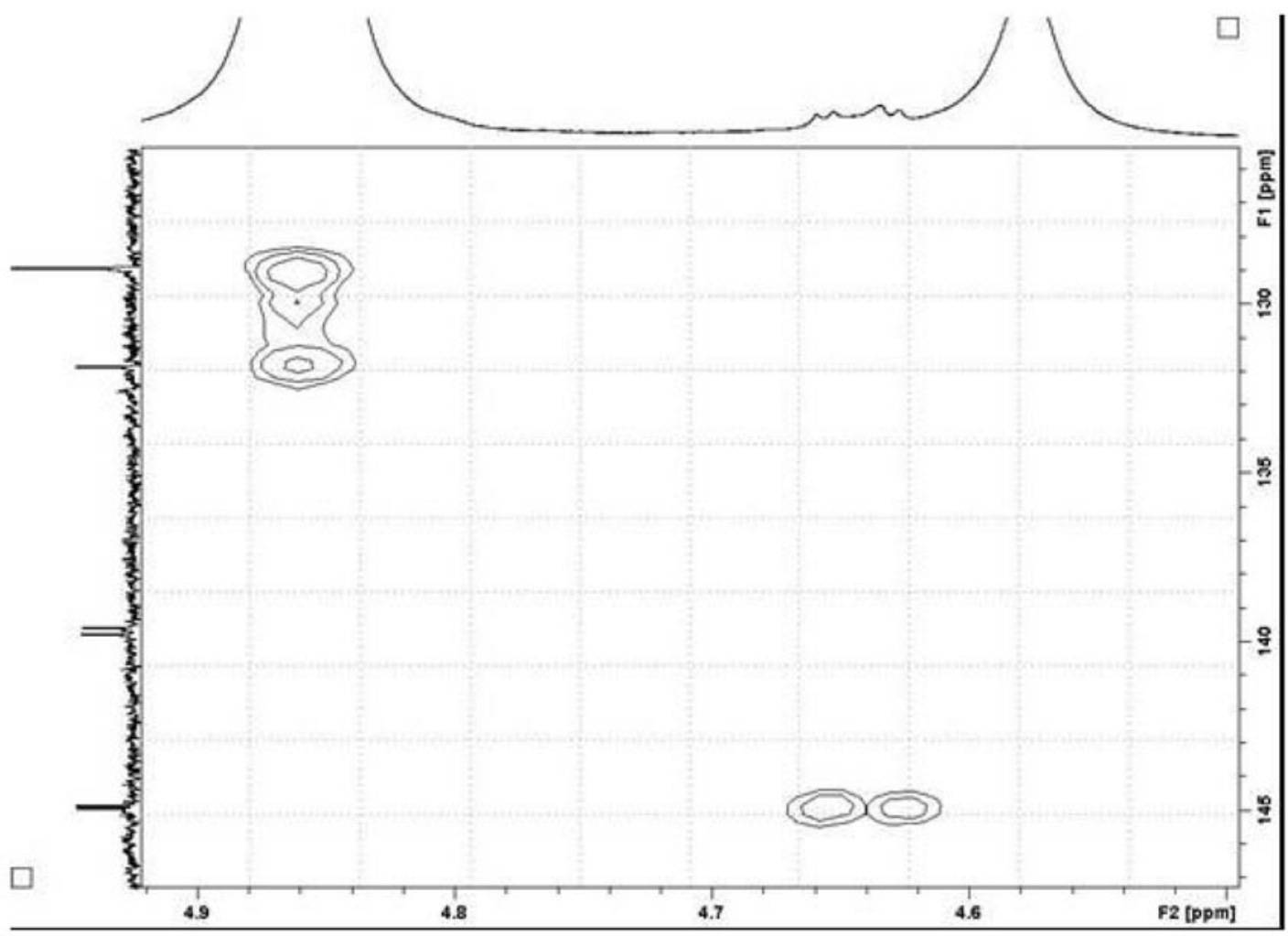

Figure S37. HMBC spectrum of compound 2 (expansion). 
Vol. 20, No. 4, 2009

Garcez et al.

$\mathrm{S} 23$

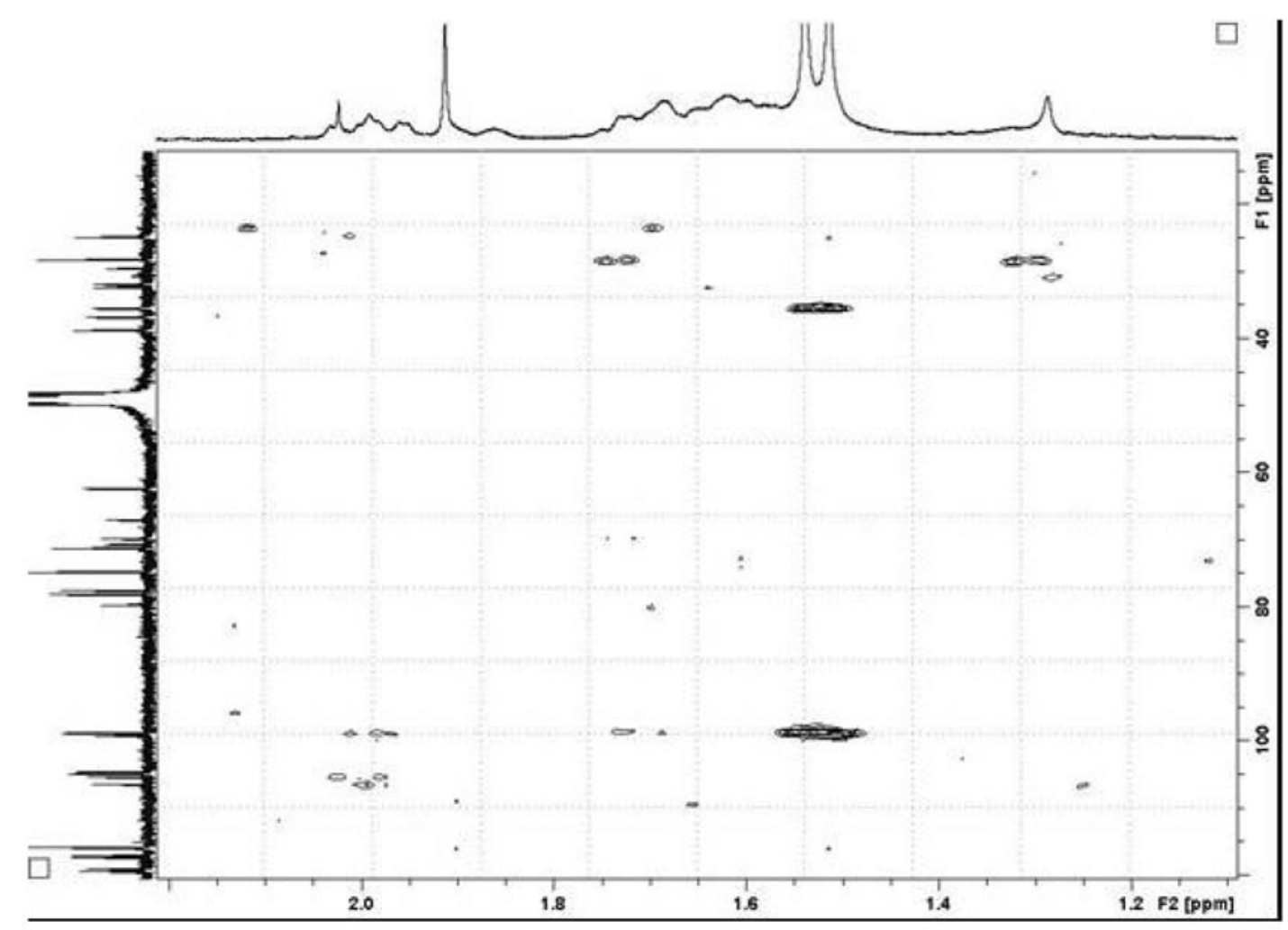

Figure S38. HMBC spectrum of compound 2 (expansion).

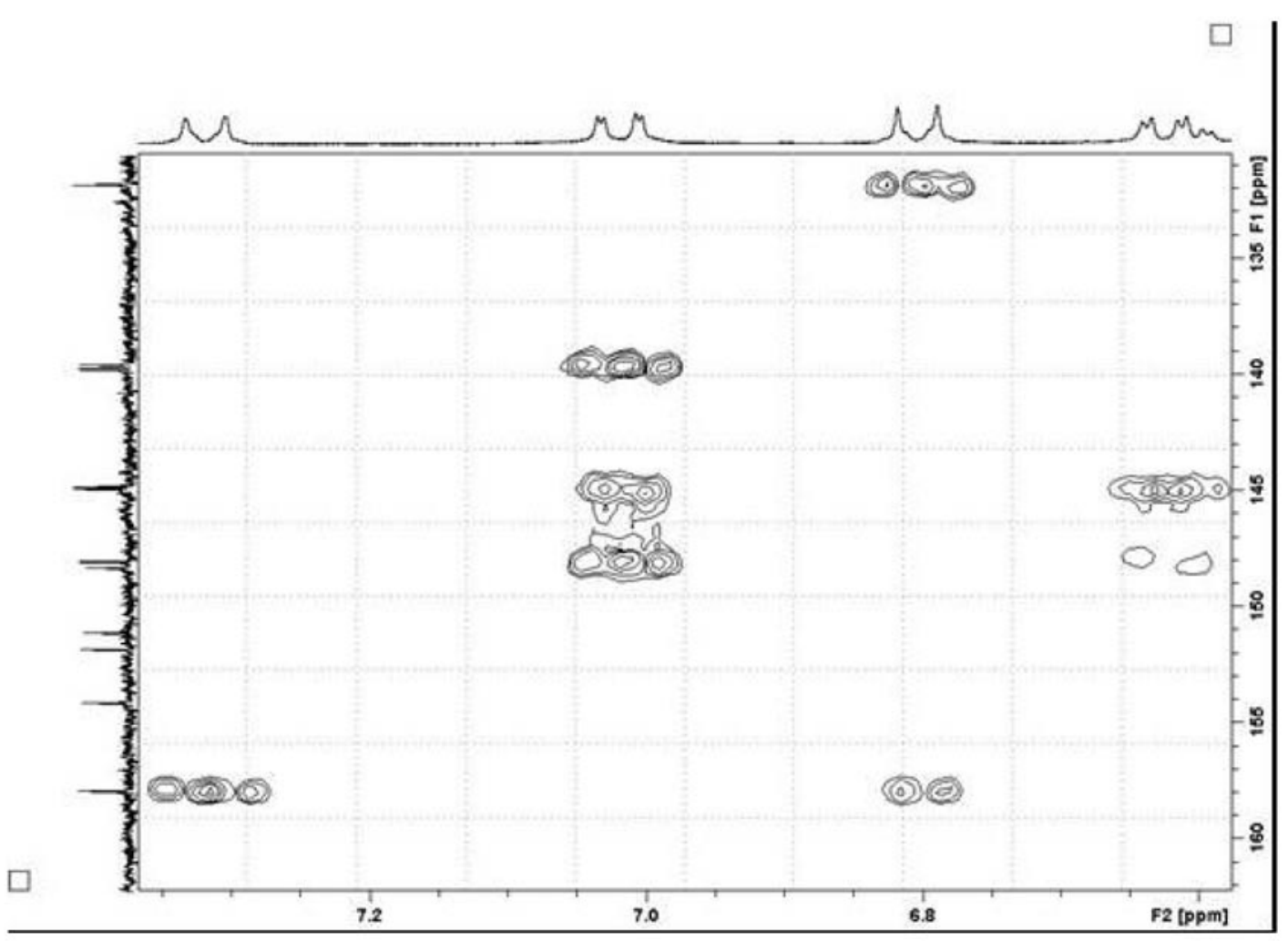

Figure S39. HMBC spectrum of compound 2 (expansion). 


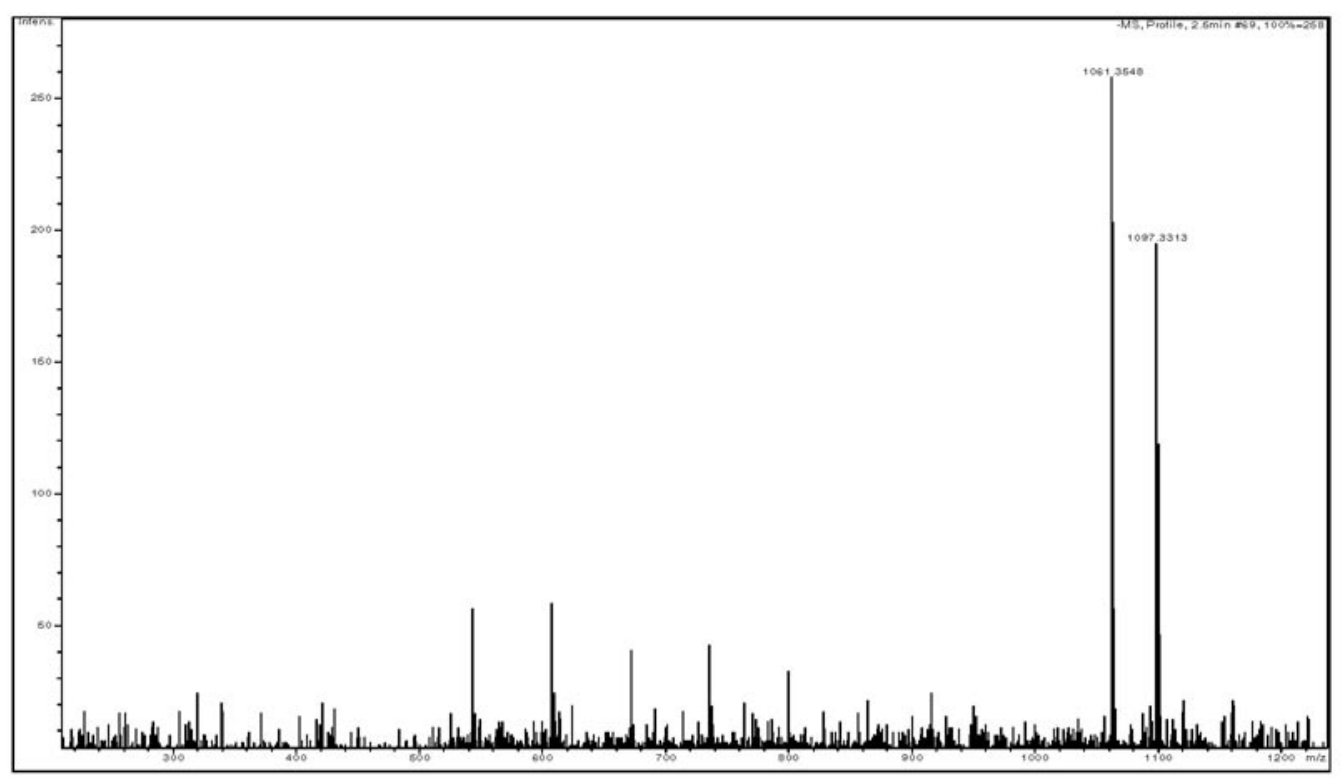

Figure S40. HRESIMS of compound 2.

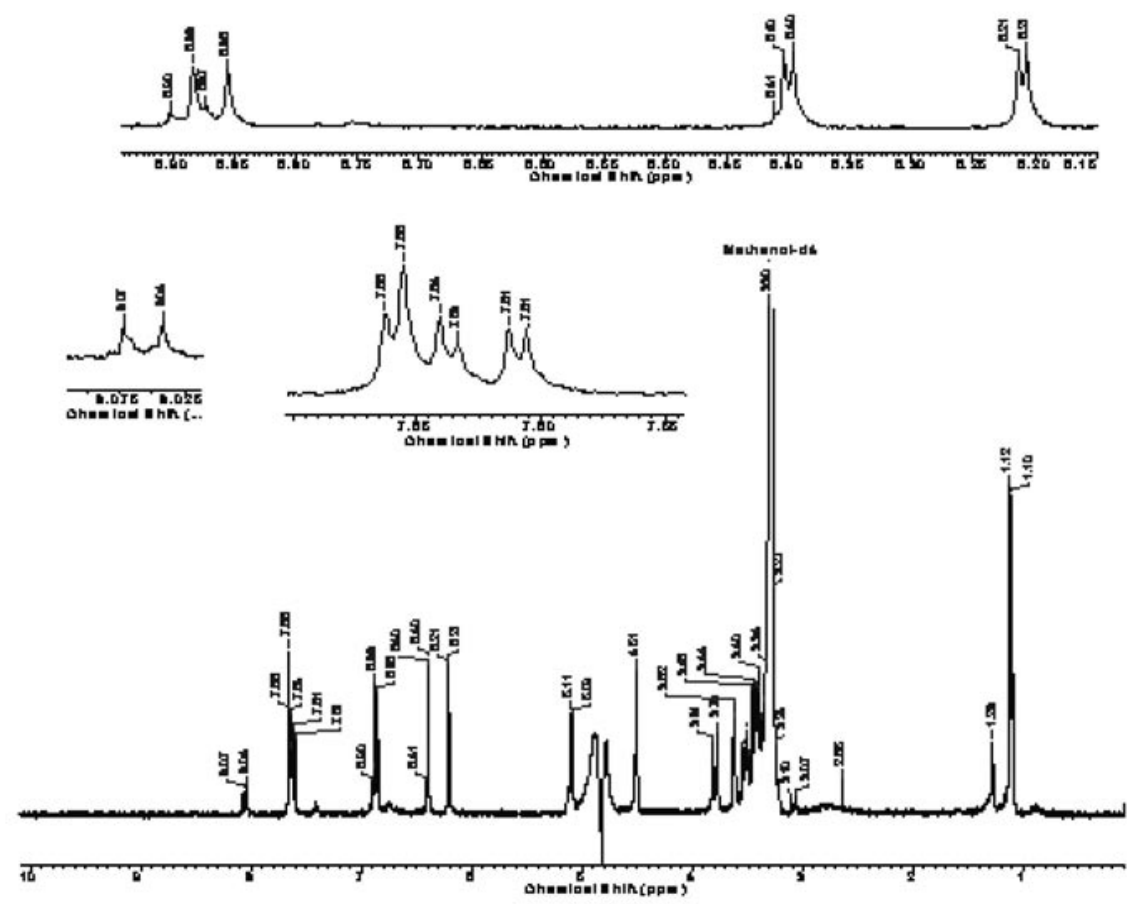

Figure S41. ${ }^{1} \mathrm{H}$ NMR spectrum ( $300 \mathrm{MHz}, \mathrm{CD}_{3} \mathrm{OD}$ ) of compound $\mathbf{3}$ (with expansions). 


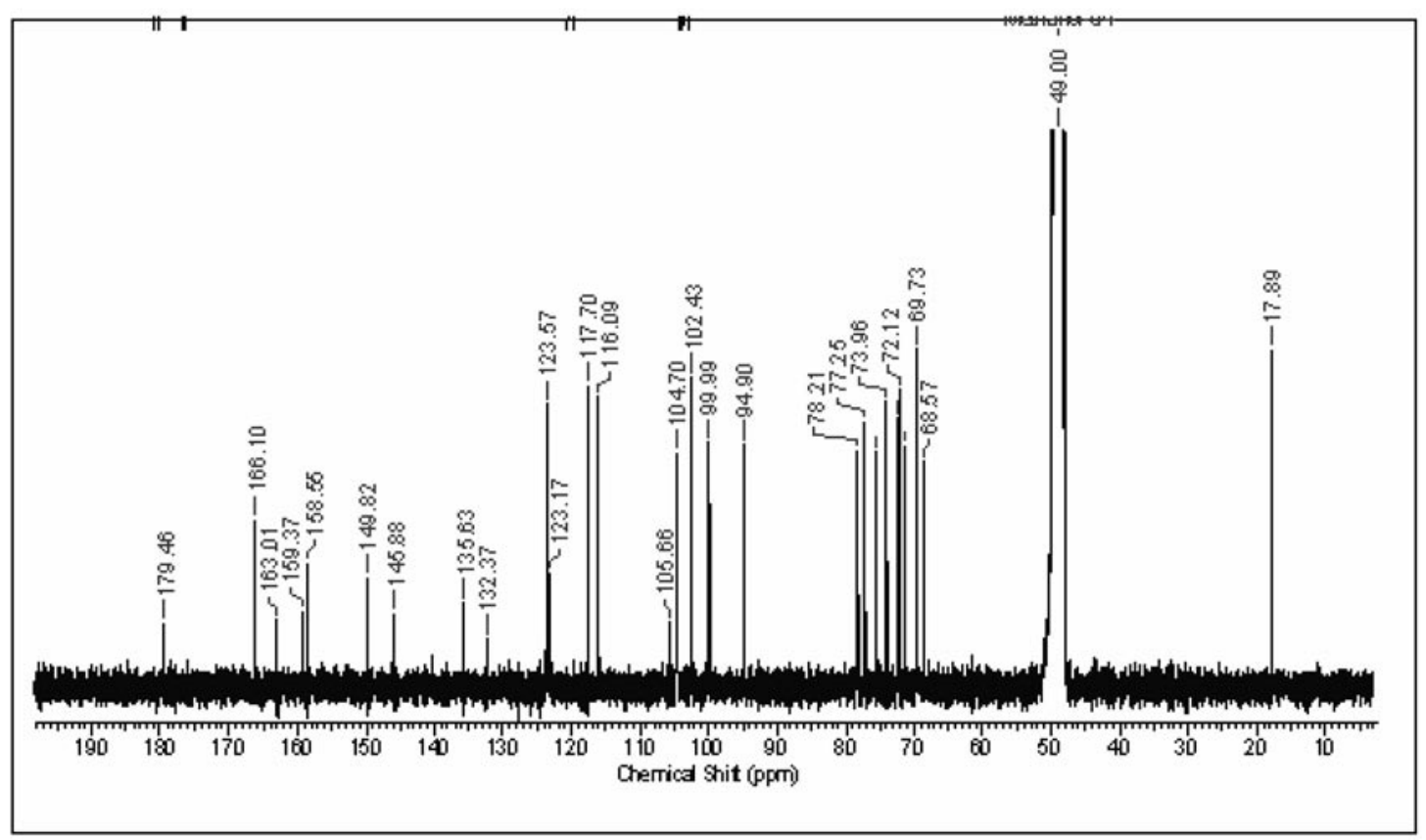

Figure S42. ${ }^{13} \mathrm{C}$ NMR spectrum $\left(75 \mathrm{MHz}, \mathrm{CD}_{3} \mathrm{OD}\right)$ of compound 3.

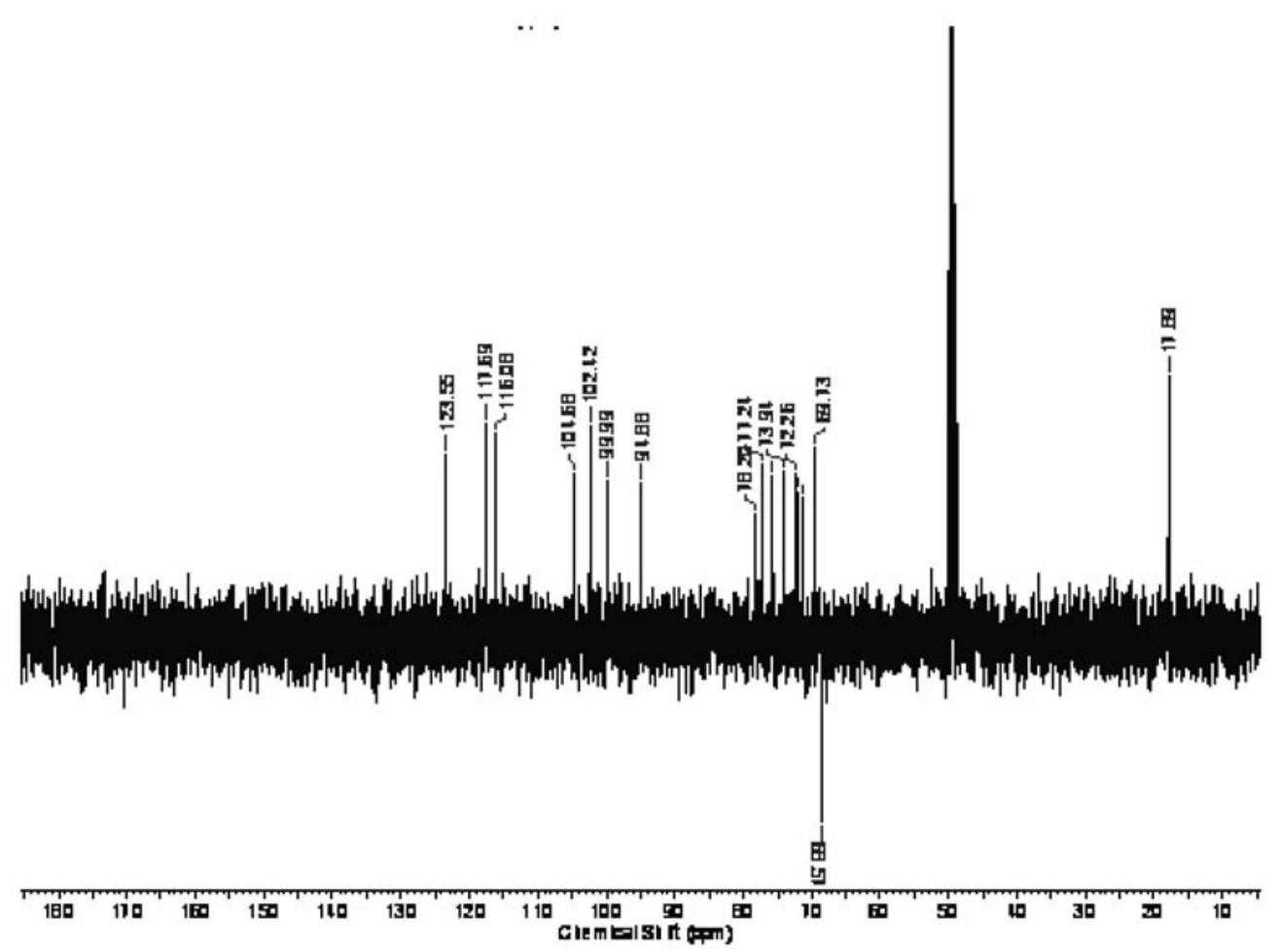

Figure S43. DEPT- $135^{\circ}$ spectrum $\left(\mathrm{CD}_{3} \mathrm{OD}\right)$ of compound 3. 